\title{
A systematic methodology for the environomic design and synthesis of energy systems combining Process Integration, Life Cycle Assessment and Industrial Ecology
}

\author{
Laboratory for Industrial Energy Systems, Ecole Polytechnique Fédérale de Lausanne \\ $\mathrm{CH}$ - 1015 Lausanne, Switzerland
}

Léda Gerber, Samira Fazlollahi, François Maréchal

Accepted by Computers and Chemical Engineering on 15.06.2013

\begin{abstract}
This paper presents a systematic methodology for sustainable process systems design, combining the principles of industrial ecology, process design and process integration, Life Cycle Assessment (LCA) and multi-objective optimization (MOO). The superstructure considers an extended decision perimeter and embeds models based either on flowsheeting software or average market technologies, for which energy and material flows are extracted from the Life Cycle Inventory (LCI) database. Therefore, the overall supply chain can be synthesized within a given action system and the systematic recyclings identified. The methodology can be used to design eco-industrial parks or urban systems, to identify the best conversion pathways of resources or waste, or to fix the optimal value of environmental taxes. It is illustrated by an application to the environomic design of an urban energy system. This case study considers multiple energy services to be supplied and waste to be treated, with their seasonal variations, indigenous and imported resources, as well as different candidate conversion technologies. Results demonstrate that integrating an environmental objective in the design procedure leads to consider different system configurations than if only economic aspects are considered. The problematic of the optimal value of a $\mathrm{CO}_{2} \operatorname{tax}$ is as well addressed.
\end{abstract}

\section{Nomenclature}

$\dot{E}_{p}^{-}$net electrical power produced by system at the operating conditions of period $p$, in $\mathrm{MW}_{e}$

$\dot{E}_{t}^{-}$electrical power produced by the turbines of the cycle, in $\mathrm{MW}_{e}$

$\dot{f} u_{p}$ quantity of functional unit involved during period $p$

$\dot{I}_{O}$ impact due to the operation phase

$\dot{m}_{\text {ext }}$ extracted mass flow rate from EGS, in $\mathrm{kg} / \mathrm{s}$

$\dot{m}_{f}$ mass flow rate of geothermal steam passing through the flash system turbine, in $\mathrm{kg} / \mathrm{s}$

$\dot{m}_{i n j}$ injected mass flow rate in EGS, in $\mathrm{kg} / \mathrm{s}$

$\dot{m}_{i}$ mass flow rate of emission of substance $i$ from flash system condensers, in kg- $i / \mathrm{kg}$-geofluid

$\dot{m}_{\text {mkup }}$ mass flow rate of make-up water for EGS, in $\mathrm{kg} /$

$\dot{m}_{\text {scal }}$ quantity of scaling and residues from EGS to be disposed, in $\mathrm{kg} / \mathrm{s}$ 
$\dot{Q}_{\text {max }}^{-}$district heating network installed capacity, in $\mathrm{MW}_{t h}$

$\dot{Q}_{p}^{-}$district heating requirement during period $p$, in $\mathrm{MW}_{t h}$

$\eta$ exergy efficiency of the conversion system, in \%

$c_{e}^{-}$selling price of electricity, in $\mathrm{USD} / \mathrm{kWh}_{e}$

$C_{\text {inv,an }}$ annualized total investment costs, in USD/yr

$C_{i n v, D H}$ investment costs associated with the district heating network, in USD

$C_{i n v, E G S}$ investment costs associated with the EGS construction

$C_{i n v, t o t}$ total investment costs of EGS, conversion system and district heating network, in USD

$C_{i n v, w}$ investment costs associated with equipment $w$, in USD

$c_{o, E G S}$ specific operating costs of EGS, in USD $/ \mathrm{h}$

$c_{o, t}$ specific operating costs of conversion technology $t$, in USD $/ \mathrm{h}$

$c_{q}^{-}$selling price of district heating, in $\mathrm{USD} / \mathrm{kWh}_{t h}$

$e_{i}$ emission factor of substance $i$ from the flash system condensers, in $\mathrm{kg}-i / \mathrm{kg}$-geofluid

$e_{C O 2, N G C C}$ specific $\mathrm{CO} 2$ emissions of electricity production from NGCC, in $\mathrm{kg} \mathrm{CO} 2-\mathrm{eq} / \mathrm{kWh} \mathrm{h}_{e}$

$e_{C O 2, N G C C}$ specific $\mathrm{CO} 2$ emissions of heating production from natural gas boiler, in kg $\mathrm{CO} 2-$ $\mathrm{eq} / \mathrm{kWh}_{t} h$

$E_{C O 2, a v}$ yearly avoided life-cycle CO2-equivalent emissions, in $\mathrm{kg} \mathrm{CO} 2-\mathrm{eq} / \mathrm{yr}$

$I_{C}$ impact due to the construction phase

$I_{E}$ impact due to the end-of-life phase

$I_{F U}$ final impacts per functional unit

$l_{\text {wat }}$ water losses in EGS, in \%

$L_{w f}$ losses and required make-up of working fluid in binary cycles, in $\mathrm{kg} / \mathrm{yr}$

$l_{w f}$ yearly losses of working fluid in binary cycles, in $\%$

$M_{k}$ required quantity of auxiliary material $k$

$M_{w f}$ initial quantity of working fluid in binary cycles, in $\mathrm{kg}$

$n_{w}$ number of wells

$n_{e c}$ number of LCI elements associated with construction phase

$n_{e e}$ number of LCI elements associated with end-of-life phase

$n_{e o}$ number of LCI elements associated with operation phase

$R_{a n}$ annual revenue, in $\mathrm{USD} / \mathrm{yr}$

$s$ success factor in achieving the EGS sub-surface plant construction, in $\%$

$T_{\text {out }}$ outlet temperature at which hot source is cooled, in ${ }^{\circ} \mathrm{K}$ 
$t_{p}$ duration of period $p$, in $\mathrm{h}$

$T_{a}$ ambient temperature, in ${ }^{\circ} \mathrm{K}$

$T_{\text {in }}$ inlet temperature of the hot source, in ${ }^{\circ} \mathrm{K}$

$T_{l m}$ logarithmic mean temperature, in ${ }^{\circ} \mathrm{K}$

$t_{p b}$ payback period, in yr

$t_{y r}$ expected lifetime of the EGS reservoir, in yr

$v_{k}$ reference quantity of auxiliary material $k$

$v_{\text {scal }}$ quantity of scaling and residues per mass unit of geothermal water, in kg-residues/kggeofluid

$x_{d}$ decision variables of the non-linear MOO problem

$y_{w f}$ thermodynamic properties of working fluid in binary cycles

$z$ EGS construction depth, in $\mathrm{m}$

CHP Combined Heat and Power

EGS Enhanced Geothermal Systems

IPCC Intergovernmental Panel on Climate Change

Kalina Kalina cycle based on the KCS-11 design

LCA Life Cycle Assessment

LCI Life Cycle Inventory

LCIA Life Cycle Impact Assessment

MILP Mixed Integer Linear Programming

MINLP Mixed Integer Non-Linear Programming

MOO Multi-Objective Optimization

NGCC Natural Gas Combined Cycle

ORC Organic Rankine Cycle

ORC-2 ORC with two evaporation levels

ORC-d ORC with an intermediate draw-off at the turbine

ORC-s supercritical ORC 


\section{Introduction}

Industrial ecology aims at identifying in a given system the possible energy and material exchanges that allow for mitigating the use of resources and the environmental impacts of human activities, in order to design sustainable economies (Allenby and Richards (1994)). The closing of material loops by the exchange of waste, by-products and energy among different industries is termed as industrial symbiosis, by analogy with a natural ecosystem (Ehrenfeld and Gertler (1997)). Applications of industrial symbioses may concern industrial complexes (Singh et al. (2007)) or urban systems (Berkel et al. (2009)). The design and synthesis of an industrial symbiosis can be realized by applying process design techniques, in order to systematically identify the optimal material and energy flow exchanges in a given system. For example, Diwekar and Shastri (2010) propose a systems approach combining process design techniques and industrial ecology for green process design. Urban et al. (2010) combines as well the two approaches to design technological-ecological synergy networks, with applications both for industries and residential houses. In addition to economic aspects, environmental performances of the industrial symbiosis have as well to be considered. This can be done by integrating Life Cycle Assessment (LCA) in the design of such systems. Singh et al. (2007) introduces such an approach in the design of industrial symbioses, while Mattila et al. (2012) discusses in details the application of LCA for the environmental assessment of industrial symbioses. In order to study and simulate complex interconnected systems such as energy systems, Davis et al. (2009) propose a methodology that integrates LCA into agent-based models. This last approach has the advantage to account for the diversity of stakeholders involved in decisions related with such complex systems. However, it does not include process design and process integration techniques, which account for the decision variables at the level of the technology. Such techniques allow in addition to identify the optimal system configurations without defining a priori scenarios.

In parallel, the integration of environmental impacts in the conceptual process design procedure has gained considerable interest in the last decade. In a previous study, we proposed a methodology for the systematic integration of LCA in process systems design (Gerber et al. (2011a)). The results highlighted the importance of impacts linked with the logistics, the auxiliary materials and with the off-site emissions, due to the extended perimeter that is considered to conduct a LCA and to the use of a Life Cycle Inventory (LCI) database. However, for products or services that can be produced with different pathways, current LCI databases like ecoinvent ${ }^{\circledR}$ (Frischknecht et al. (2005)) assume a fixed unit process chain, or supply chain, for each product or waste. In these supply chains, pre-defined fractions of each unit process represent the market share of each option. Therefore, process design options may be biased due to the choices of the options in such supply chains, and their systematic synthesis is not possible. Moreover, the systematic identification of recycling possibilities of waste or co-products generated by processes operating at a given location can not be performed with such databases. Therefore, the design of industrial symbioses is not possible with the methodology presented in our previous study.

Regarding the environomic synthesis of supply chains, several methodologies have already been proposed. Hugo and Pistikopoulos (2005) introduce a strategy to synthesize supply chains, considering both costs and cumulated life cycle impacts in a multi-objective mixed integer linear programming (MILP) optimization. Guillén-Gosálbez et al. (2008) propose as well a similar approach to directly extract the optimal flowsheet configurations from the process superstructure for the design of chemical processes, using mixed integer non-linear programming (MINLP). Extending this approach, Guillén-Gosálbez and Grossmann (2010) present a strategy for the multi-objective optimization of chemical supply chains, including uncertainties in the environmental impact model. In the field of energy systems, Cucek et al. (2012) propose as well a MINLP formulation considering LCA for the synthesis of bioenergy supply chains. However, none of these studies considers the LCI database itself as part of the superstructure to be used for supply chain synthesis.

From the literature review in the fields of industrial ecology and conceptual process design, 
it appears that no methodology has been proposed, combining at the same time process design, process integration, industrial ecology and LCA, and considering the LCI database as a part of the superstructure. Such a methodology, allowing to use dynamically LCI databases, would be useful for process synthesis, industrial parks design, or for the allocation of resources and waste at the scale of a territory.

The objective of the present study is therefore to propose a systematic methodology for process systems design that combines the above described principles and allows for identifying the optimal configurations, independently of the agents behavior. It is an approach proposing engineering solutions, and therefore the dynamics of the system agents are not modeled. The method can only be used for preliminary system design, in order to identify the promising candidate configurations of a system, for which a detailed engineering has still to be done. The methodology is illustrated by an application to the design and synthesis of an urban energy system considering both economic and environmental criteria.

\section{Methodology}

This section presents the developed methodology. It includes the computational framework (sec.2.1), the superstructure generation and its extension to the supply chain synthesis (sec.2.2), the LCI database disaggregation (sec.2.3), and the MILP optimization model (sec.2.4).

\subsection{Computational framework}

Figure 1 shows the developed computational framework, which is used for the simulation, the design and the optimization of energy systems. It is adapted from Gassner and Maréchal (2009a) and Gerber et al. (2011a), to account for the seasonal (i.e. multi-period) variations in the operation of the overall energy system. A methodology for this aspect has been proposed in Fazlollahi and Maréchal (2011). The framework is as well extended to perform simultaneous mass and energy integration. The different operating periods are assumed to be independent. Thus, mass and energy storage are not considered between two sequential periods.

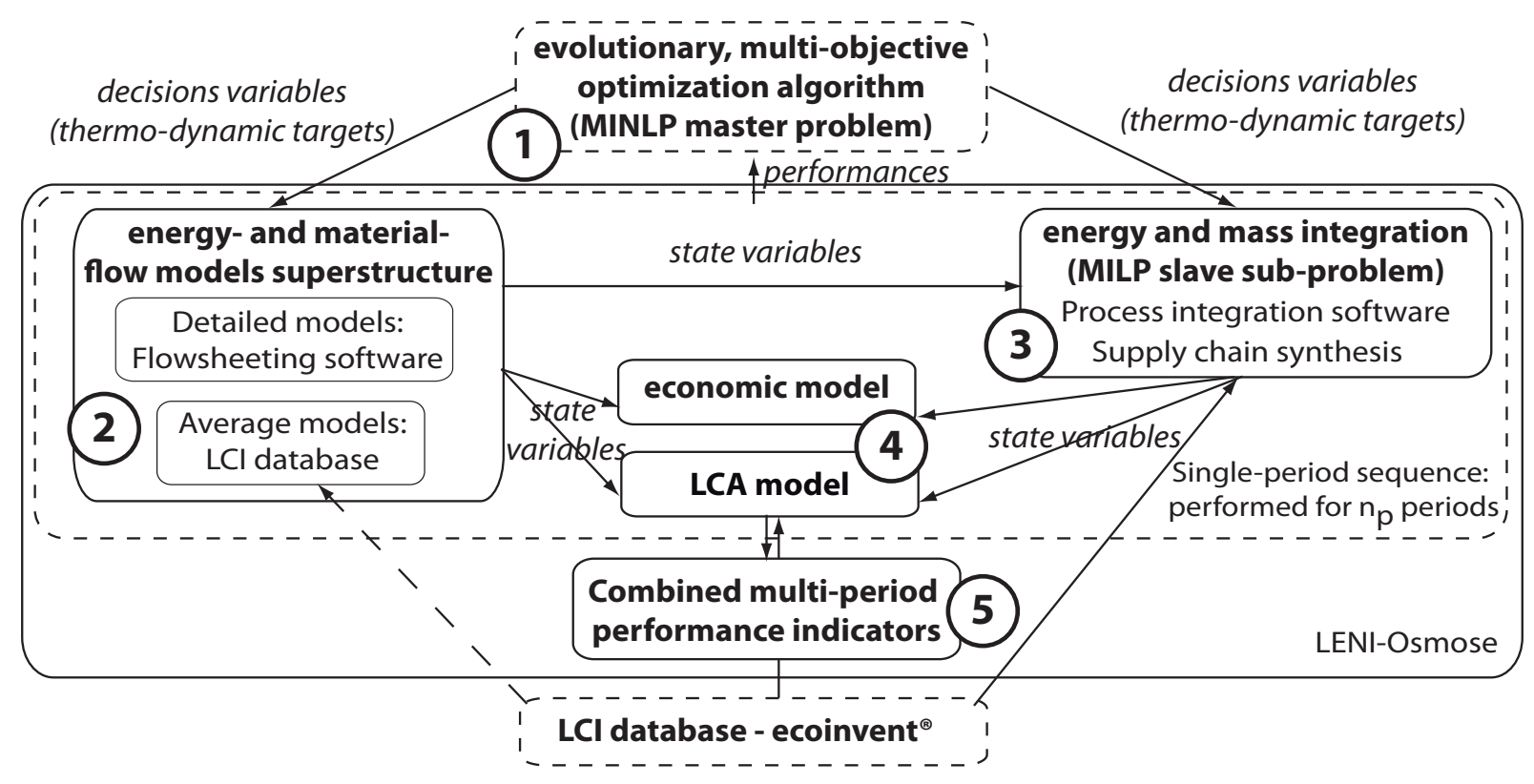

Figure 1: Computational framework used for system design and optimization

The optimization problem is a MINLP multi-objective model. The goal is to minimize simultaneously the costs and the environmental impacts. The problem is decomposed in two stages: 
a master problem and a slave sub-problem.

The master problem is a MINLP (step 1 on Fig. 1), subject to the slave MILP sub-problem (step 3 on Fig. 1). It deals with sizing the process unit variables. It is solved as a multiobjective optimization of the non-linear investment and impacts of the system, and of the linear operating costs. These three objectives are calculated during the post-calculation phase for each independent operation period (step 4 on Fig. 1) and combined to represent the overall performance of the system at the end of the computation sequence (step 5 on Fig. 1). A multiobjective evolutionary algorithm is used to solve the master MINLP problem (Molyneaux et al. $(2010))$

A superstructure including the different technological options is built and the thermo-economic models of these components are developed. This superstructure embeds either detailed models using flowsheeting software or average models, for which data are extracted from the LCI database. The energy and mass flows for each process unit are calculated based on a given set of operating conditions. These results are used as input data in the slave optimization model (step 3 on Fig. 1). The slave optimization concerns the combined mass and energy integration of the system. It aims at minimizing either the system operating costs, or the linear environmental impacts, or the operating costs including the environmental taxes. For these two last objectives, it is necessary to calculate a linear approximation of the environmental impact of the different processes embedded in the superstructure prior the post-calculation phase. For this purpose, a link is created between the LCI database ecoinvent ${ }^{\circledR}$ (Frischknecht et al. (2005)) and the process integration software in order to systematically extract the impacts of the corresponding processes. Moreover, the decision system is extended to a larger action system than a single process. This involves to extend the superstructure with average technologies or resources, for which detailed flowsheet models are not necessary. In this case, the data of average technologies in the LCI database are sufficient in precision and can be used for writing simple models.

\subsection{Decision system extension and superstructure generation}

The general concept developed to account for supply chain synthesis in the methodology is described in Figure 2. A distinction is made between the overall system and the action system. The overall system represents the real system to be considered for calculating the environmental impacts or the total costs. The action system is the one where decisions can be effectively taken in order to decrease the impacts or the costs.

The action system contains a superstructure of units representing processes or technologies $(U)$. It is used to synthesize the supply chain for obtaining final services or products $(B)$, or to convert waste or available resources $(R)$. Each unit has a series of sources and sinks $(S)$, representing material and energy streams that are necessary inputs or product outputs. The units are either detailed flowsheet models, or simple models based on the average technologies of the LCI database. Each unit generates emissions and extractions $(E m)$ to and from the environment, creating impacts $(I)$. Each unit has an associated operating cost $\left(C O_{u}\right)$, investment cost $\left(C I_{u}\right)$, an environmental impact $\left(I_{u}\right)$ and an associated utilization factor $\left(\mathrm{f}_{\mathrm{u}}\right)$. The supply chain synthesis aims at determining the optimal values of the $f_{u}$ by solving the MILP slave subproblem at the process integration step. It is then performed by establishing matches between sources and sinks, with respect to the definition of the functional unit (FU), according to the LCA methodology (ISO $(2006 \mathrm{a}, \mathrm{b})$ ). This FU can be a given quantity of product or service to be produced, or available resources to be converted or waste to be treated. This general concept is used as a basis to disaggregate in a first step the LCI database in unit processes with associated emissions and extractions. In a second step, the supply chains are re-synthesized accounting for the mass balance constraints. The possible recyclings (i.e. industrial symbioses possibilities) are identified, and the impacts on the environment or on the operating costs are minimized. 


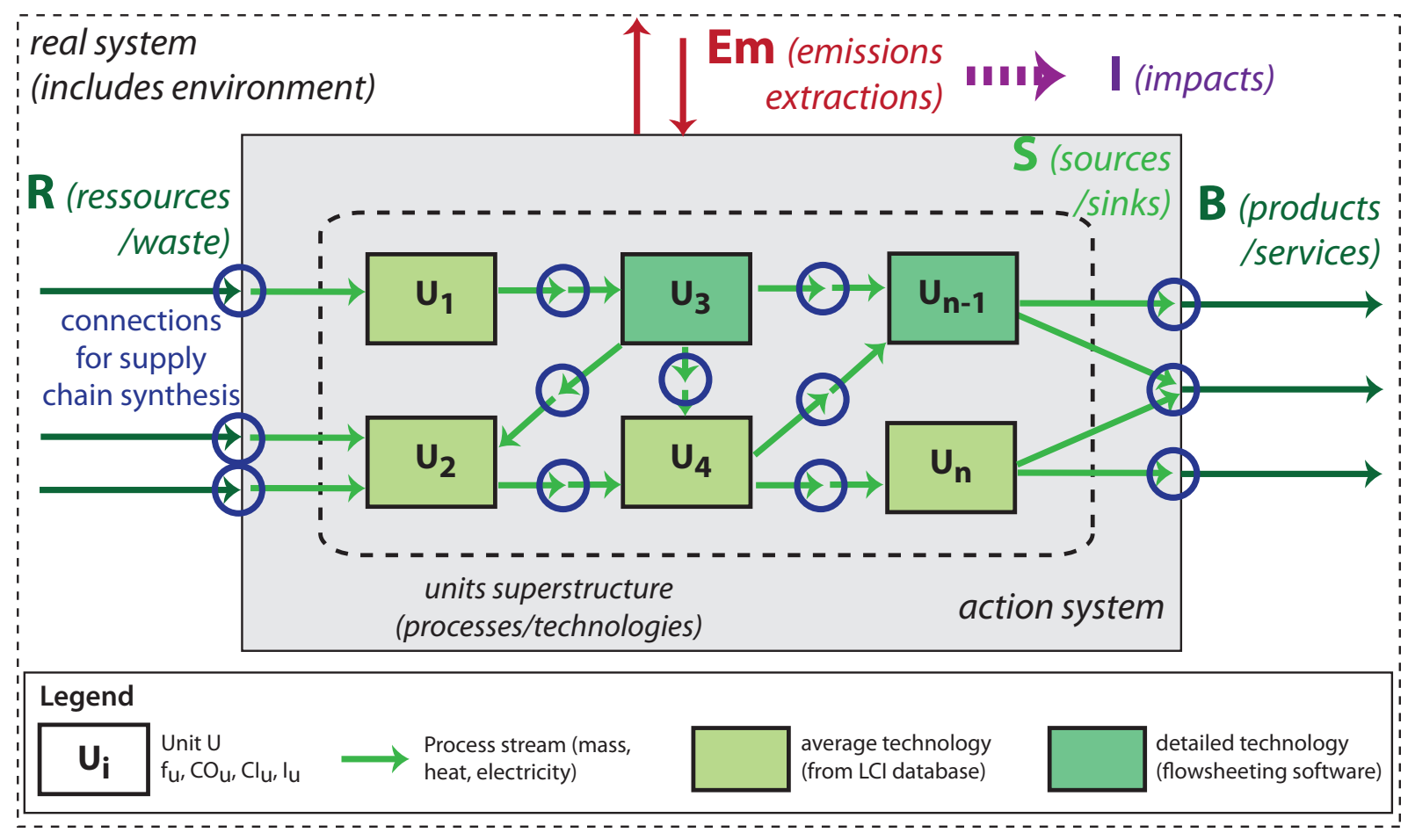

Figure 2: General concept for supply chain synthesis including data from LCI database

\subsection{LCI database disaggregation}

To disaggregate the LCI database in models of average resources or technologies, a distinction has to be made between different types of processes. Those termed here as 's-type' are fully included in the superstructure of the action system and have both sources and sinks. The processes of 'r-type' and 'p-type' are at the interface of the action system and of the environment. 'r-type' processes represent a resource delivery, and 'p-type' processes represent a product sink (Gerber et al. (2011b)). The r-type and p-type units represent the limits of the system under which decisions have to be taken. This is summarized in Figure 3.

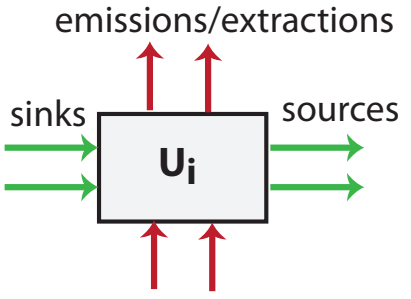

s-type

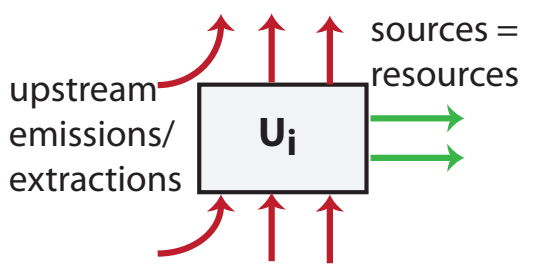

r-type

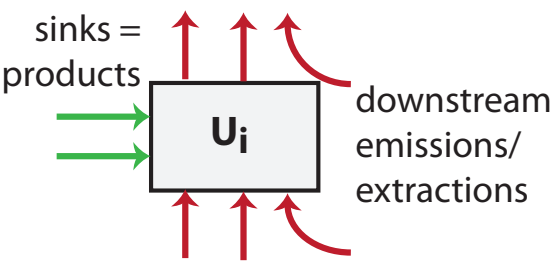

p-type

Figure 3: Differences between the s-type, r-type and p-type unit process (Gerber et al. (2011b))

The level of cut-off at which a unit process becomes a r- or p-type has to be defined considering the level at which no control is possible anymore on the processes, representing the average technology or resources available on the market. It is relatively easy to perform this operation with the data from ecoinvent ${ }^{\circledR}$, since the database offers two different formats for the information linked with the embedded processes:

1. UPR format (unit process), used for s-type. This format contains the inputs and outputs as material and energy flows, representing the sources and sinks. It includes as well the emissions and extractions generated by the process only, without upstream and downstream 
emissions.

2. Aggregated LCI format, used for $\mathrm{r}$ - and p-type. This format contains the cumulative emissions and extractions of the upstream or downstream processes.

Once the disaggregation is performed, the different processes constitute the superstructure of the average technologies and resources that are used in the next step to re-synthesize the optimal supply chain.

\subsection{MILP formulation for system synthesis}

To synthesize the optimal supply chain and account for the systematic recyclings, a MILP model is used. The constraints are put on the mass balance for each process or technology. This ensures that each source for a process finds another process as a sink, except where a certain quantity of a product or service is wanted or of a resource or waste has to be converted:

$$
\begin{gathered}
\forall s=1 \ldots n_{s}: \sum_{u=1}^{n_{u}} \mathrm{f}_{\mathrm{u}, \mathrm{p}} \cdot s_{s, u}^{+/-}\left(x_{d}\right)=0 \\
\forall r=1 \ldots n_{r}: \sum_{u=1}^{n_{u}} \mathrm{f}_{\mathrm{u}, \mathrm{p}} \cdot r_{r, u}^{+/-}\left(x_{d}\right)=R_{r, p} \\
\forall b=1 \ldots n_{b}: \sum_{u=1}^{n_{u}} \mathrm{f}_{\mathrm{u}, \mathrm{p}} \cdot b_{b, u}^{+/-}\left(x_{d}\right)=B_{b, p}
\end{gathered}
$$

where $\mathrm{f}_{\mathrm{u}, \mathrm{p}}$ is the utilization fraction at period $p$ of the process or technology $u$ of the superstructure for the considered action system. $n_{u}$ is the total number of processes embedded in the superstructure, $s_{s, u}^{+}$is the quantity of the source $s$ consumed by the process $u$, a negative sign $\left(s_{s, u}^{-}\right)$meaning a production. $s_{s, u}^{+}$is a function of the decision variables $x_{d}$ of the master MINLP problem of Figure 1. $r_{r, u}^{+}$is the quantity of resource $r$ consumed by process $u$, and $b_{b, u}^{+}$is the quantity of product $b . \dot{R}_{r, p}$ and $\dot{B}_{b, p}$ are the required quantities of resource $r$ or product $b$ that have to be converted or produced, and are defined according to the problem to be solved. Using this layer approach for each source/sink, product and resource allows to systematically identify the potential recyclings within the action system. The $f_{u}$ are the decision variables of the slave MILP sub-problem. The emissions and extractions calculation for the LCI is as well included in the MILP formulation:

$$
\forall i=1 \ldots n_{i}: \sum_{u=1}^{n_{u}} \mathrm{f}_{\mathrm{u}, \mathrm{p}} \cdot e m_{i, u, p}^{+}\left(x_{d}\right)=E m_{i, p}
$$

where $e m_{i, u, p}^{+}$is the elementary flow $i$ of the LCI emitted or extracted by the process $u$ at period $p$. Thus, a linear approximation of the impact of the system for its operation at period $p$ is already calculated during the process integration step using the Life Cycle Impact Assessment (LCIA):

$$
I_{l, p}=\sum_{i=1}^{n_{i}} E m_{i, p} \cdot F_{i, l}
$$

where $I_{l, p}$ is the impact category $l$ of the selected impact assessment method, $E m_{i, p}$ is the emission or extraction $i$ calculated in the LCI, and $F_{i, l}$ is the weighting factor to convert the LCI emission $i$ into the impact category $l$.

This impact can be used to solve the following MILP slave sub-problem. It is a modified version of the one presented in Maréchal and Kalitventzeff (1998), integrating the environmental taxes in the system operating costs. The definition of operating costs becomes thus: 


$$
\text { Min } C O_{p}=\left(\sum_{u=1}^{n_{u}} \mathrm{f}_{\mathrm{u}, \mathrm{p}} \cdot\left(C O_{u, p}+I_{u, p} \cdot c_{I}\right)+\sum_{r=1}^{n_{r}}\left(R_{r, p} \cdot c_{r}+I_{r, p} \cdot c_{I}\right)+\mathrm{E}_{\mathrm{p}}^{+} \cdot c_{e^{+}}-\mathrm{E}_{\mathrm{p}}^{-} \cdot c_{e^{-}}\right)\left(x_{d}\right)
$$

where $\mathrm{f}_{\mathrm{u}, \mathrm{p}}$ is the utilization factor of unit $u$ at period $p, C O_{u, p}$ is its operating cost, $I_{u, p}$ its impact. $c_{I}$ is the specific environmental tax associated with the impact, $R_{r, p}$ is the consumption of resource $r$ at period $p, c_{r}$ is its buying price, $I_{r, p}$ is its impact. $\mathrm{E}_{p}^{+}$and $\mathrm{E}_{u}^{-}$are the consumed and produced electricity by the system, and $c_{e^{+}}$and $c_{e^{-}}$are the specific costs for electricity buying and selling from and to the grid.

If the impact is used as the objective of the MILP slave sub-problem, the formulation becomes:

$$
\text { Min } I_{p}=\left(\sum_{u=1}^{n_{u}} \mathrm{f}_{\mathrm{u}, \mathrm{p}} \cdot I_{u, p}+\sum_{r=1}^{n_{r}} I_{r, p}+I_{\mathrm{E}_{\mathrm{p}}^{+}}-I_{\mathrm{E}_{\mathrm{p}}^{-}}\right)\left(x_{d}\right)
$$

where $I_{u, p}$ is the impact of unit $u$ at period $p, I_{r, p}$ the impact of resource $r$, and $I_{E_{p}^{+}}$and $I_{E_{p}^{-}}$ are the impact of electricity import and export from and to the grid.

For each independent period, the energy integration is as well performed. Thus, both equations (6) and (7) are as well submitted to the constraints of the heat cascade without (Linnhoff et al. (1982)) or with heat exchanges restrictions (Becker and Maréchal (2012)), depending on the problem to be solved.

\section{Application to urban systems}

\subsection{Urban systems superstructure}

The concept described for the extended action system and supply chain synthesis described in Figure 2 is used as a basis to generate the superstructure that is used for the design and synthesis of an urban system. It contains five different subsystems:

1. The available resources. These can be indigenous (e.g. biomass or geothermal energy), in which case they are limited, or imported (e.g. natural gas or oil), in which case they can be limited or not, depending on the problem to be solved.

2. The conversion technologies. These are necessary to convert the resources to final energy services or intermediate products (e.g. gasification of biomass or cogeneration engines), or to treat the waste (e.g. wastewater treatment plant).

3. The services to be supplied (e.g. heat or electricity).

4. The waste to be treated (e.g. municipal solid waste or wastewater).

5. The transfer networks. These are used when the services can not directly be delivered to the user without an intermediate (e.g. district heating network).

In addition to associated operating costs, investment, environmental impacts and mass and energy flows for a nominal size, each one of these units has a minimal and maximal sizing factor $\left(f_{\min }\right.$ and $\left.f_{\max }\right)$. It depends on if the unit is a process $\left(f_{\mathrm{u}}=1\right)$, a utility with unlimited use $\left(f_{\max }=\right.$ unlimited $)$ or with limited use $\left(f_{\max }=\right.$ limited $)$. The units are either detailed models using flowsheeting software, or average technologies extracted from the LCI database. The example of such a superstructure is displayed in Figure 4, with both detailed models and average technologies from the LCI database ecoinvent ${ }^{\circledR}$ (Frischknecht et al. (2005)).

Following the developed methodology for the extraction of average technologies from the LCI database, the conversion technologies are s-type processes, with an incremental impact, and the resources are r-type processes, with a cumulated impact. Thus, there is no double-counting of 


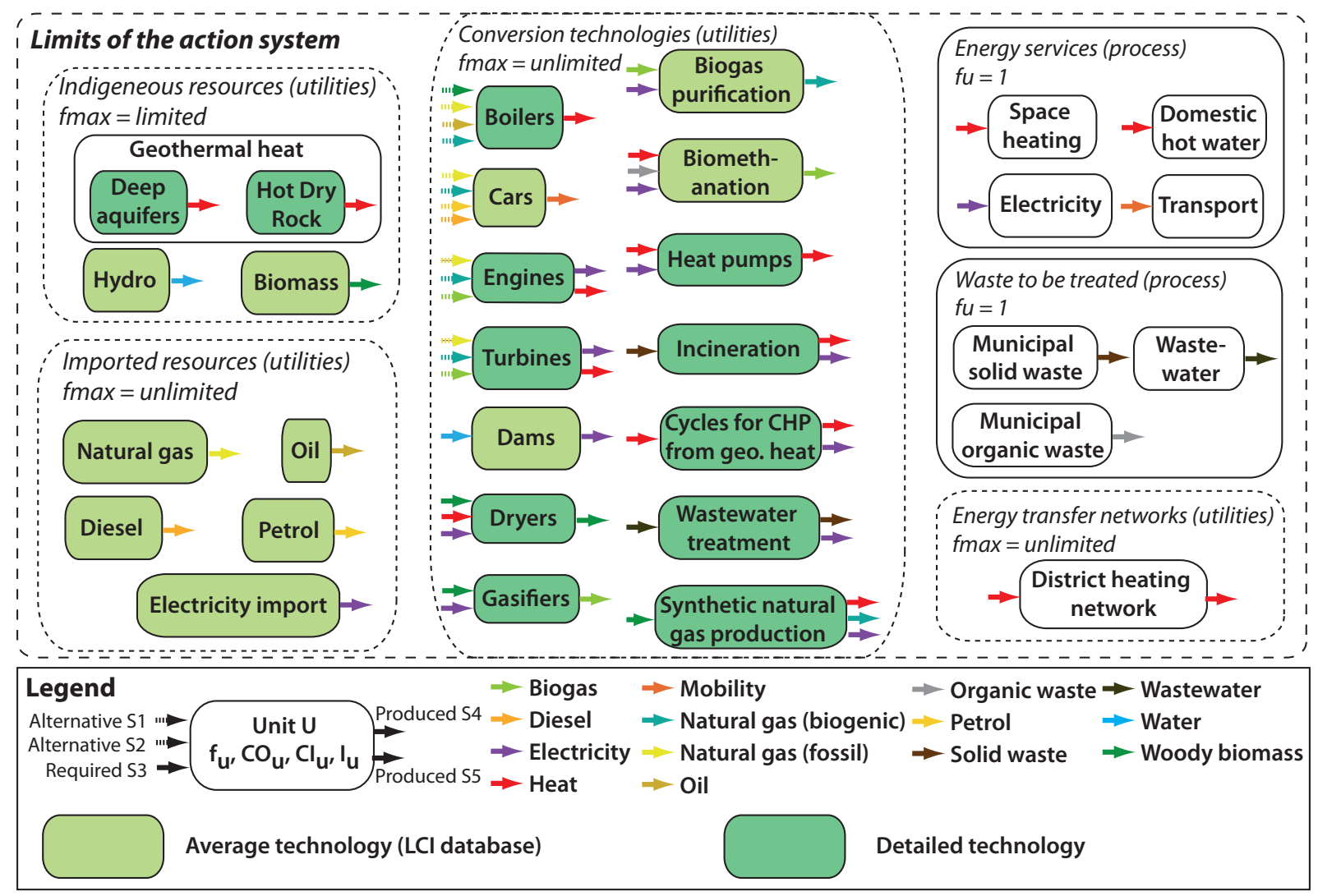

Figure 4: Example of a superstructure for urban energy systems synthesis

the emissions while synthesizing the supply chains for the overall system. The references used for the different physical, economic and environmental models of the units embedded in the superstructure are given in Table 6 for the conversion technologies and 7 of the Appendix for the resources .

\subsection{Case study description}

A city of Switzerland, La Chaux-de-Fonds, with a population of approximately 40,000 and located at $1000 \mathrm{~m}$ of altitude, is taken as an application case study. It has already a district heating network with an installed capacity of $47 \mathrm{MW}_{t h}$. The heat requirements are presently supplied in priority by a Municipal Solid Waste Incineration (MSWI) plant. It has a steam network that allows for Combined Heat and Power (CHP) production. The remaining heat requirements are supplied by a natural gas boiler and a wood boiler. The objective is to redesign and optimize this urban energy system in a future perspective, considering the different energy services to be supplied and the waste to be treated, as well as the available indigenous resources. Both economic and environmental criteria are considered. The value that has to be fixed for a $\mathrm{CO}_{2}$ tax in order to favor economically the systems configurations reducing the environmental impact is as well considered. This illustrates how the methodology can be applied to calculate the impact of an environmental policy by showing the real cost of such a tax on the overall life cycle. The superstructure of Figure 4 is used, and displays a list of the services and waste to be considered, as well as of the available indigenous resources, the potential imported resources and the potential energy conversion technologies. 


\subsubsection{Functional unit}

The functional unit of the considered system, both for evaluating the economic and environmental performance, is the yearly energy services to be supplied to the city, as well as the yearly waste treatment and disposal.

\subsubsection{Energy services}

The energy services to be supplied include space heating and hot water, electricity and mobility. The seasonal requirements in space heating and hot water have been characterized using the methodology of Girardin et al. (2010), and are displayed in Figure 5. These data are used as a basis to calculate the total heating requirements for the buildings connected to the district heating network.

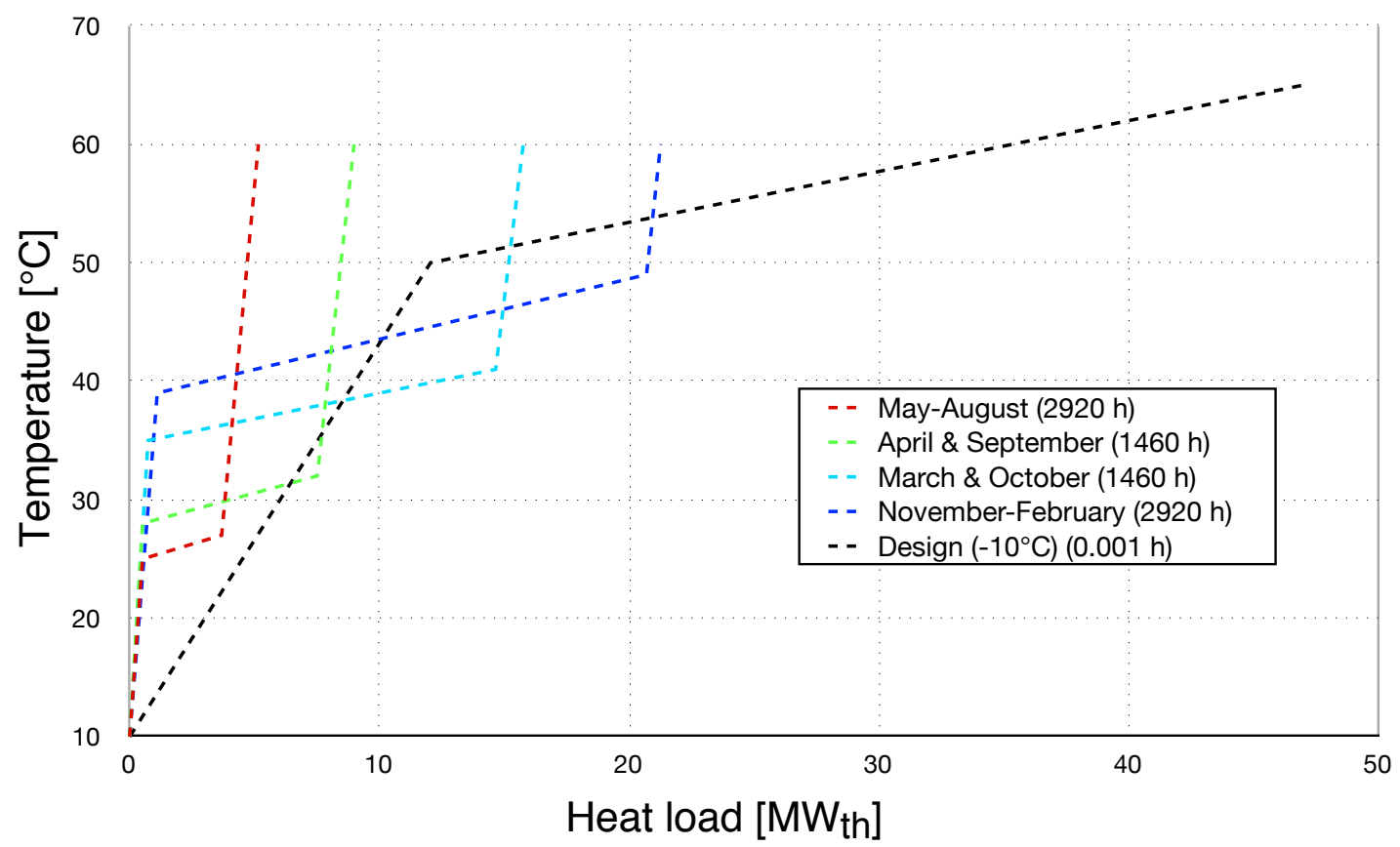

Figure 5: Seasonal demand profiles in space heating and hot water for the buildings connected to the district heating network of the case study

The seasonal requirements are used as a basis to define the number of considered periods. In June, the MSWI plant is closed for revision. This month is thus considered as a separate period from May, July and August, with the same heating requirement. A total number of 6 periods is hence considered.

The monthly electricity requirements for overall Switzerland (OFEN (2010)) are used to estimate the total electricity requirements per capita corresponding to each period. The seasonal demand in electricity per capita, accounting for the losses on the grid, is displayed in Table 1.

According to the Federal Office of Statistics (OStat (2010)), the mobility requirements in Switzerland are currently around 11,392 person $\mathrm{km} / \mathrm{y}$ and per capita. This value is used to calculate the overall mobility requirement, assuming no seasonal variation.

\subsubsection{Waste}

The waste to be treated considered here include municipal solid waste, wastewater and organic waste. 55,000 t are incinerated each year in the MSWI plant. The latter includes facilities for composting yearly $3500 \mathrm{t}$ of organic waste. This amount could be used to satisfy a part of the requirements in energy services via a biomethanation unit. It is therefore included in the case 


\begin{tabular}{|l|l|}
\hline Period & $\begin{array}{l}\text { Demand, in } \\
\mathbf{k W}_{e} / \text { capita }\end{array}$ \\
\hline May, July \& August & 0.886 \\
June & 0.903 \\
April \& September & 0.931 \\
March \& October & 1.020 \\
November-February & 1.110 \\
Design (peak load) & 1.4 \\
\hline
\end{tabular}

Table 1: Seasonal electricity requirements per capita for the case study

study, assuming no seasonal variation. From the data available in Muller et al. (2008), the design value taken for the flow entering a wastewater treatment plant (WWTP) is equal to $300 \mathrm{~m}^{3}$ per year and per capita, assuming no seasonal variation.

\subsubsection{Indigenous resources}

Four different indigenous renewable resources are considered for the case study: residual wood from forest industry, geothermal resources, considering both deep aquifers and Hot Dry Rock, and hydraulic energy.

According to Steubing et al. (2010), the sustainable biomass potential in Switzerland for forest energy wood, industrial wood residues and wood from landscape maintenance is equal to $34.9 \mathrm{PJ}_{t h}$ per year. Brought back to the case study, this gives a total yearly potential of 49,086 $\mathrm{MW}_{t h}$. No seasonal variation is assumed in the wood availability, but it can be distributed among the periods.

For the geothermal potential, two types of resources are considered: deep aquifers and Hot Dry Rock, the latter being exploitable as an Enhanced Geothermal System (EGS). The potential deep aquifer is located at a depth of $1450 \mathrm{~m}$. Its temperature is $51^{\circ} \mathrm{C}$, its reinjection temperature $30^{\circ} \mathrm{C}$, its expected mass flow rate $15 \mathrm{~kg} / \mathrm{s}$, and its available thermal power $1.1 \mathrm{MW}_{\text {th }}$ (Working group PDGN (2010)). For EGS, the results presented in Gerber and Maréchal (2012b) are used, and five typical configurations are considered, with different potential construction depths for the EGS: a 6000m EGS with a Kalina cycle for CHP, a 6500m EGS with a supercritical Organic Rankine Cycle (ORC) for electricity production, a 8000m EGS with a double-flash system for CHP, a 9500m EGS with a single-flash system and a bottoming ORC for electricity production and a 9500m EGS with an ORC including an intermediate draw-off for CHP.

Hydro-electricity production represents around $56 \%$ of the Swiss electricity production (OFEN (2010)) and has thus to be considered in the base mix of Swiss electricity. Using the data from OFEN (2010), the hydro-electricity production can be estimated to $0.536 \mathrm{~kW}_{e}$ per capita in average.

\subsubsection{District heating network}

The district heating network allows for supplying the heat to the users, the demand being displayed in Figure 5. The return and supply temperatures considered here depend on the season and are displayed in Table 2 .

Since the network is already existing, the costs and the impacts from its construction are not accounted for. It is used as a constraint for the heat supply from the different technologies, avoiding the direct exchanges with the heat demand from the users. The methodology from Becker and Maréchal (2012) for the heat exchanges with restriction is applied for this. 


\begin{tabular}{|l|c|c|}
\hline Period & Supply $\mathbf{T}$, in ${ }^{\circ} \mathbf{C}$ & Return $\mathbf{T}$, in ${ }^{\circ} \mathbf{C}$ \\
\hline May, July \& August & 90 & 38 \\
June & 90 & 38 \\
April \& September & 92 & 39 \\
March \& October & 96 & 41 \\
November-February & 99 & 43 \\
Design (peak load) & 112 & 45 \\
\hline
\end{tabular}

Table 2: Return and supply temperatures from the district heating network for the case study

\subsection{Multi-objective optimization}

The objective for the MILP slave sub-problem is to minimize the operating costs, as stated in Eq. (6). This includes as well the costs of the life-cycle $\mathrm{CO}_{2}$ equivalent emissions and multiplied by the $\mathrm{CO}_{2}$-tax. The latter is given as one of the decision variables of the MINLP master MOO problem.

Three independent optimization objectives are selected:

1. The investment costs, to be minimized:

$$
\text { Min } C I_{\text {tot }}=\sum_{t=1}^{n_{t}} \max \left(C I_{t}\left(\mathrm{f}_{\mathrm{t}}, x_{d}, c_{I}\right)\right)_{n_{p}}+\sum_{r=1}^{n_{r}} \max \left(C I_{r}\left(\mathrm{f}_{\mathrm{r}}, x_{d}, c_{I}\right)\right)_{n_{p}}
$$

where $n_{t}$ and $n_{r}$ are the total number of technologies and of resources embedded in the superstructure. $C I_{t}$ and $C I_{r}$ are the investment costs linked with technology $t$ or resource $r$, for which the maximum value is retained over all the independent periods $n_{p} . \mathrm{f}_{\mathrm{t}}$ and $\mathrm{f}_{\mathrm{r}}$ are the utilization factors of the technologies and of the resources, and are the decision variables of the MILP slave sub-problem. $x_{d}$ are the decision variables of the MINLP master problem, and $c_{I}$ is the $\mathrm{CO}_{2}$ tax, as well given as a decision variable of the master MINLP master problem.

2. The annual operating costs, to be minimized:

$$
\text { Min } C O_{a n}=\sum_{p=1}^{n_{p}} t_{p} \cdot\left(\sum_{t=1}^{n_{t}} \dot{C} O_{t}\left(\mathrm{f}_{\mathrm{t}}, x_{d}, c_{I}\right)+\sum_{r=1}^{n_{r}} \dot{C} O_{r}\left(\mathrm{f}_{\mathrm{r}}, x_{d}, c_{I}\right)\right)
$$

where $t_{p}$ is the operating time associated with period $p, \dot{C O}_{t}$ is the operating cost of technology $t, n_{r}$ is the number of indigenous or imported resources, $C O_{r}$ is the total operating cost of resource $r$, and $\mathrm{f}_{\mathrm{r}}$ are the utilization factors of resources, decision variables of the MILP sub-problem.

3. The annual life-cycle $\mathrm{CO}_{2}$-equivalent emissions per capita, to be minimized:

$$
\begin{aligned}
\text { Min } I_{\text {an }, \text { cap }}= & \\
& \frac{\sum_{t=1}^{n_{t}}\left(\max \left(I_{C, t}\right)_{p}+\max \left(I_{E, t}\right)_{n_{p}}+\sum_{p=1}^{n_{p}} t_{p} \cdot \dot{I}_{O, t}\right)\left(\mathrm{f}_{\mathrm{t}}, x_{d}, c_{I}\right)}{n_{c a p} \cdot t_{y r}} \\
& +\frac{\sum_{r=1}^{n_{r}}\left(\max \left(I_{C, r}\right)_{p}+\max \left(I_{E, r}\right)_{n_{p}}+\sum_{p=1}^{n_{p}} t_{p} \cdot \dot{I}_{O, r}\right)\left(\mathrm{f}_{\mathrm{r}}, x_{d}, c_{I}\right)}{n_{c a p} \cdot t_{y r}}
\end{aligned}
$$


where $I_{C, t}$ and $I_{C, r}$ are the construction impacts of technology $t$ and resource $r, I_{E, t}$ and $I_{E, r}$ are the end-of-life impact. Their maximum value is retained over the $n_{p}$ periods. $\dot{I}_{O, t}$ and $\dot{I}_{O, r}$ are the operating impacts, $n_{c a p}$ the population of the considered urban area and $t_{y r}$ is the system lifetime, assumed to be 25 years.

The whole space of potential configurations has to be explored by the evolutionary algorithm. To ensure this, the selection of each one of the different technologies embedded in the superstructure for the solving of the MILP slave sub-problem is given as a decision variable of the MINLP master problem. All the decision variables are given in Table 3.3. Some of them are generated using a multi-period strategy, to adapt the system operating conditions to the seasonal variations. The economic assumptions are summarized in Table 4.

\begin{tabular}{|c|c|c|c|c|}
\hline Name & $\begin{array}{l}\text { Type of } \\
\text { variable }\end{array}$ & $\begin{array}{l}\text { Multi- } \\
\text { period }\end{array}$ & Range & Unit \\
\hline $\mathrm{CO}_{2} \operatorname{tax} c_{I}$ & continuous & no & {$[0 ; 0.2]$} & $€ / \mathrm{kgCO}_{2}$-eq \\
\hline $\begin{array}{l}\text { Electricity production from MSWI } \\
\text { plant }\end{array}$ & continuous & yes & {$[1000 ; 5000]$} & $\mathrm{kW}_{e}$ \\
\hline Biomass usage over period $p$ & integer & yes & {$[0 ; 1]$} & - \\
\hline Evaporation temperature of HT HP & continuous & yes & {$[5 ; 40]$} & ${ }^{\circ} \mathrm{C}$ \\
\hline Evaporation temperature of LT HP & continuous & yes & {$[5 ; 40]$} & ${ }^{\circ} \mathrm{C}$ \\
\hline $\begin{array}{l}\text { Condensation temperature of } \mathrm{HT} \\
\mathrm{HP}\end{array}$ & continuous & yes & {$[30 ; 80]$} & ${ }^{\circ} \mathrm{C}$ \\
\hline $\begin{array}{l}\text { Condensation temperature of } \mathrm{LT} \\
\mathrm{HP}\end{array}$ & continuous & yes & {$[30 ; 80]$} & ${ }^{\circ} \mathrm{C}$ \\
\hline EGS configuration choice ${ }^{\mathrm{a}}$ & integer & no & {$[0 ; 5]$} & - \\
\hline Selection of biomethanation of OW & integer & no & {$[0 ; 1]$} & - \\
\hline Selection of diesel car & integer & no & {$[0 ; 1]$} & - \\
\hline Selection of petrol car & integer & no & {$[0 ; 1]$} & - \\
\hline Selection of fossil NG car & integer & no & {$[0 ; 1]$} & - \\
\hline Selection of biogenic SNG car & integer & no & {$[0 ; 1]$} & - \\
\hline Selection of air biomass dryer & integer & no & {$[0 ; 1]$} & - \\
\hline Selection of steam biomass dryer & integer & no & {$[0 ; 1]$} & - \\
\hline Selection of biogas engine & integer & no & {$[0 ; 1]$} & - \\
\hline Selection of fossil NG engine & integer & no & {$[0 ; 1]$} & - \\
\hline Selection of biogenic SNG engine & integer & no & {$[0 ; 1]$} & - \\
\hline $\begin{array}{l}\text { Selection of air gasification of } \\
\text { biomass for engine }\end{array}$ & integer & no & {$[0 ; 1]$} & - \\
\hline $\begin{array}{l}\text { Selection of steam gasification of } \\
\text { biomass for engine }\end{array}$ & integer & no & {$[0 ; 1]$} & - \\
\hline $\begin{array}{l}\text { Selection of air gasification of } \\
\text { biomass for turbine }\end{array}$ & integer & no & {$[0 ; 1]$} & - \\
\hline $\begin{array}{l}\text { Selection of steam gasification of } \\
\text { biomass for turbine }\end{array}$ & integer & no & {$[0 ; 1]$} & - \\
\hline Selection of biogas turbine & integer & no & {$[0 ; 1]$} & - \\
\hline $\begin{array}{l}\text { Selection of OW biogas purification } \\
\text { to SNG }\end{array}$ & integer & no & {$[0 ; 1]$} & - \\
\hline $\begin{array}{l}\text { Selection of thermochemical wood } \\
\text { conversion to SNG }\end{array}$ & integer & no & {$[0 ; 1]$} & - \\
\hline
\end{tabular}

Table 3: Decision variables used for the MOO of the case study for urban systems

a 0: no EGS, 1: 6000m EGS, Kalina cycle, 2: 6500m EGS, ORC (supercritic.) with R134a, 3: 8000m EGS, 2-flash, 4: 9500m EGS, 1-flash \& ORC with iso-butane, 5: 9500m EGS, ORC (draw-off) with cyclo-butane 


\begin{tabular}{|l|l|l|}
\hline Parameter & Value & Unit \\
\hline Wood cost & 0.050 & $€ / \mathrm{kWh}_{t h}$ \\
Hydro-electricity cost & 0.160 & $€ / \mathrm{kWh}_{e}$ \\
UCTE electricity mix cost & 0.160 & $€ / \mathrm{kWh}_{e}$ \\
Imported natural gas cost & 0.078 & $€ / \mathrm{kWh}_{t h}$ \\
Light fuel oil cost & 0.083 & $€ / \mathrm{kWh}_{t h}$ \\
Petrol cost & 1.88 & $€ / \mathrm{kg}$ \\
Diesel cost & 1.75 & $€ / \mathrm{kg}$ \\
Lifespan & 25 & $\mathrm{y}$ \\
Interest rate & 6 & $\%$ \\
\hline
\end{tabular}

Table 4: Economic assumptions used for the multi-objective optimization

The optimal system configurations have then to be compared in terms of economic and of environmental performance with the current situation, in order to identify the most suitable ones.

For the economic performance, the payback period is used and expressed as:

$$
t_{p b}=\frac{C I_{a n} \cdot t_{y r}}{C O_{a n, r e f}-C O_{a n}\left(c_{I}\right)}
$$

where $C I_{a n}$ are the annualized investment costs of the configuration to be compared, $C O_{a n, r e f}$ are the yearly operating costs of the current situation, estimated to $95 \mathrm{M} €$, and $C O_{a n}$ are the yearly operating costs of the configuration.

For the environmental performance, the relative reduction in the $\mathrm{CO}_{2}$-equivalent emissions is used and expressed as:

$$
R c o 2_{I}=\frac{I_{a n, c a p, r e f}-I_{a n, c a p}}{I_{a n, c a p, r e f}}
$$

where $I_{\text {an,cap,ref }}$ is the environmental impact of the current situation, estimated to $4.0 \mathrm{t}$ of $\mathrm{CO}_{2}$-eq per capita, and $I_{a n \text {,cap }}$ is the impact of the configuration to be compared.

\subsection{Results}

Figure 6 shows the Pareto curve obtained for the tri-objective environomic optimization for the studied urban system.

Five clusters are identified on the Pareto curve, each one of them corresponding to the selection of one of the EGS configurations embedded in the superstructure. The curve shows clear trade-offs between the investment costs and the yearly operating costs, and between the investment costs and the $\mathrm{CO}_{2}$ emissions. Inside each cluster, there is as well a trade-off between the $\mathrm{CO}_{2}$ emissions and the two other economic objectives, though the variations are less important than between the clusters. This is illustrated by Figure 7, which shows the details of cluster E with a more precise scale for the $\mathrm{CO}_{2}$ emissions.

As illustrated by Figure 7 for cluster E, the introduction of an environmental objective in the optimization procedure leads to consider configurations that would be suboptimal in a pure economic optimization and would not be kept by the optimizer in the final configurations. However, these environomic system configurations lead to a lower environmental impact for a penalty in investment and operating costs.

\subsubsection{Typical configurations}

Figure 8 displays the investment costs at Fig. 8(a), the operating costs at Fig. 8(b) and the life-cycle $\mathrm{CO}_{2}$ emissions at Fig. 8(c) associated with 10 typical configurations. For each cluster 


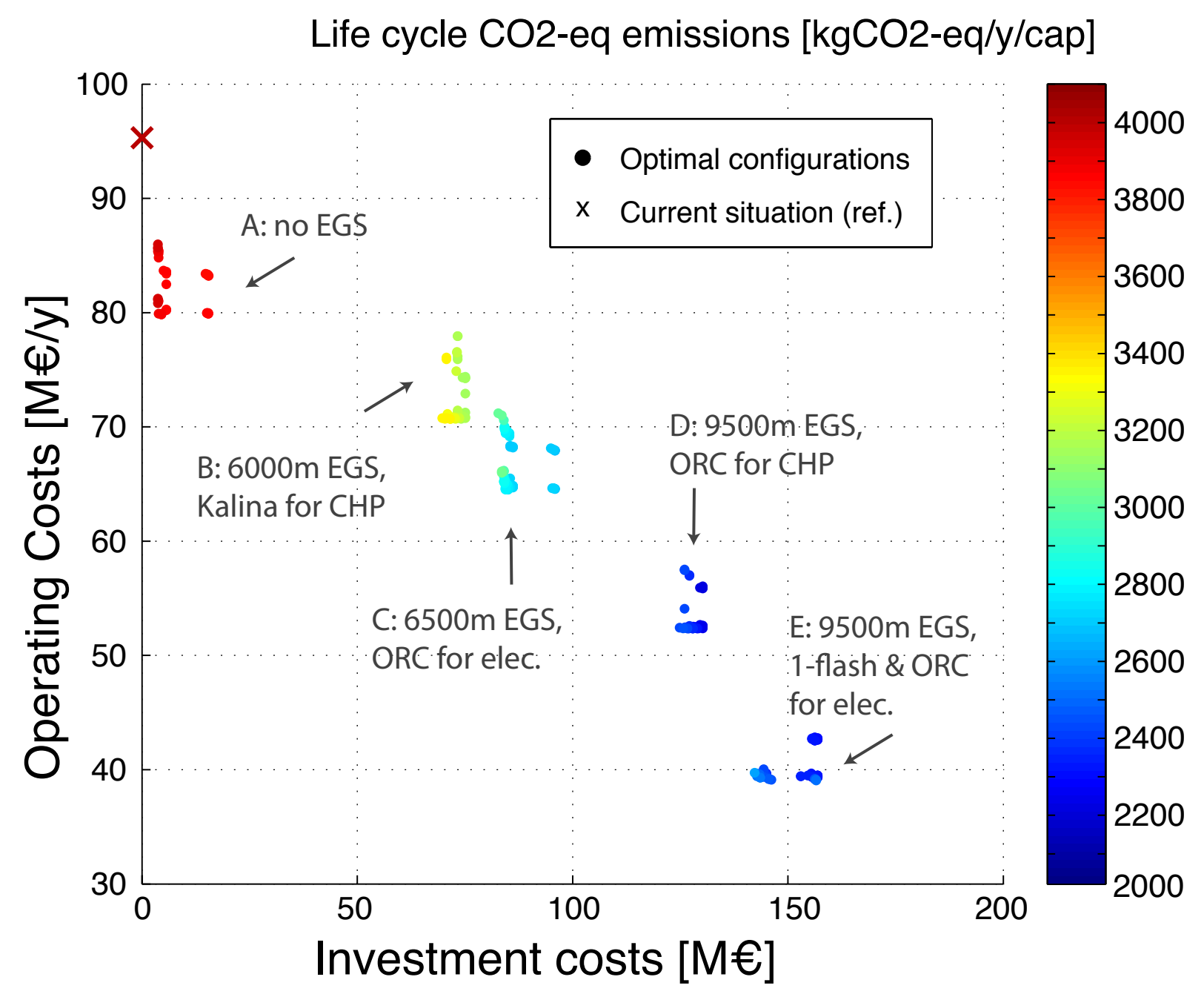

Figure 6: Pareto curve obtained by the tri-objective environomic optimization. The current situation is as well displayed on the graph

of the Pareto curve (A,B,C,D,E), one pure economic (1) configuration and one environomic (2) configuration are analyzed. The operating costs and $\mathrm{CO}_{2}$ emissions of the current situation (Ref) are as well displayed for comparison.

The investments are dominated by the geothermal technologies, which have important costs associated with the drilling of the wells. The investment of a wood-to-SNG conversion unit is as well significant for the configurations where this technology is selected. When compared with the current situation, all the optimal configurations lead to a reduction in the operating costs. These are dominated by the electricity either from hydro-electricity or from UCTE mix import, and by the import of fossil fuels for transport. The contribution of the $\mathrm{CO}_{2}$ tax is low in all the cases, since the highest $\mathrm{CO}_{2}$ tax selected in the optimal configuration is equal to $c_{I}=0.002 € / \mathrm{kgCO}_{2}-$ eq. This is due to the inclusion of the technology selection in the decisions variables of the MOO master problem, ensuring that the configurations with a good environmental performance are selected even with a low tax. All the optimal configurations, except A1, lead to a reduction in the environmental impact. The $\mathrm{CO}_{2}$ emissions are dominated by the electricity UCTE mix import and by the emissions due to transport.

The major difference between the economic and the environomic configurations is the use of a wood-to-SNG conversion unit, of a biomethanation unit for organic waste, and, in some of the cases, the exploitation of a deep aquifer for geothermal energy. Both economic and environomic configurations use EGS at various depths with different cycles, either with or without heat 


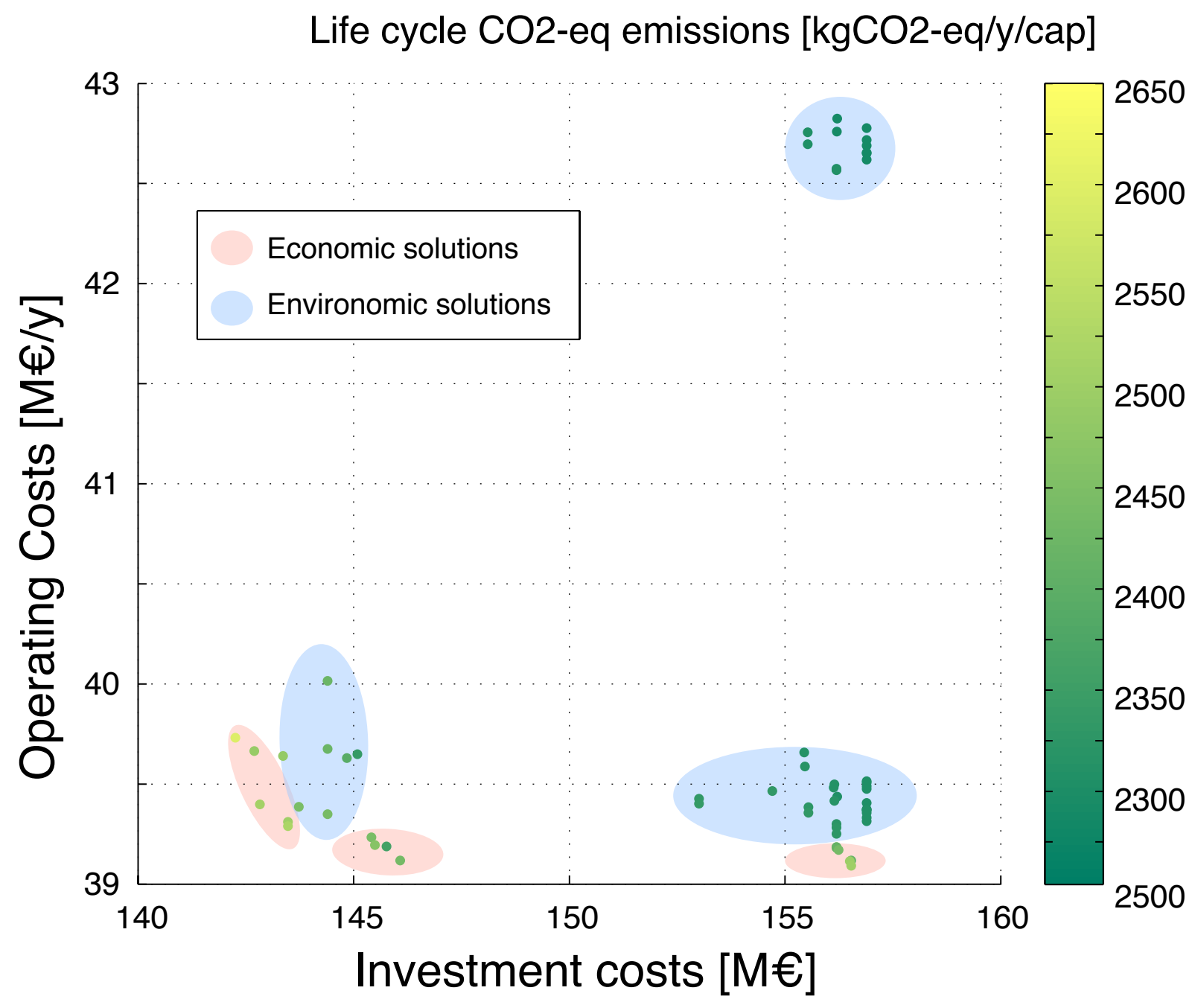

Figure 7: Detail of cluster E of the Pareto curve on Figure 6

production in addition to the electricity production.

The operating costs and the environmental impacts linked with district heating and electricity can be potentially both reduced in an important way by relying on waste treatment technologies and on local resource. However, the costs and impacts linked with transport remain high even when the full potential of wood is converted to SNG and used in cars. This demonstrates the importance of accounting for the availability of local renewable resources and waste.

Four important aspects linked to the application of the methodology to the case study can be identified: 1) the seasonal character of energy services and thus of the system operation 2) the optimal pathways for resources or waste conversion and allocation 3) the selection of the technologies embedded in the superstructure 4) the competition or synergies between different supply chains.

Seasonal operation The developed methodology allows for accounting for the seasonal variation in the energy services demand and for adapting the technology selection and its operating conditions to these constraints. This aspect is illustrated by configuration E1 in Figure 9, for which the system operation per capita is represented for three different periods. The technologies or resources showing a seasonal variation are highlighted with their flows in color, while the ones with constant operation are shaded and their flows are displayed in grey.

As displayed in Figure 9, the share between electricity and heat from the MSWI plant, the 


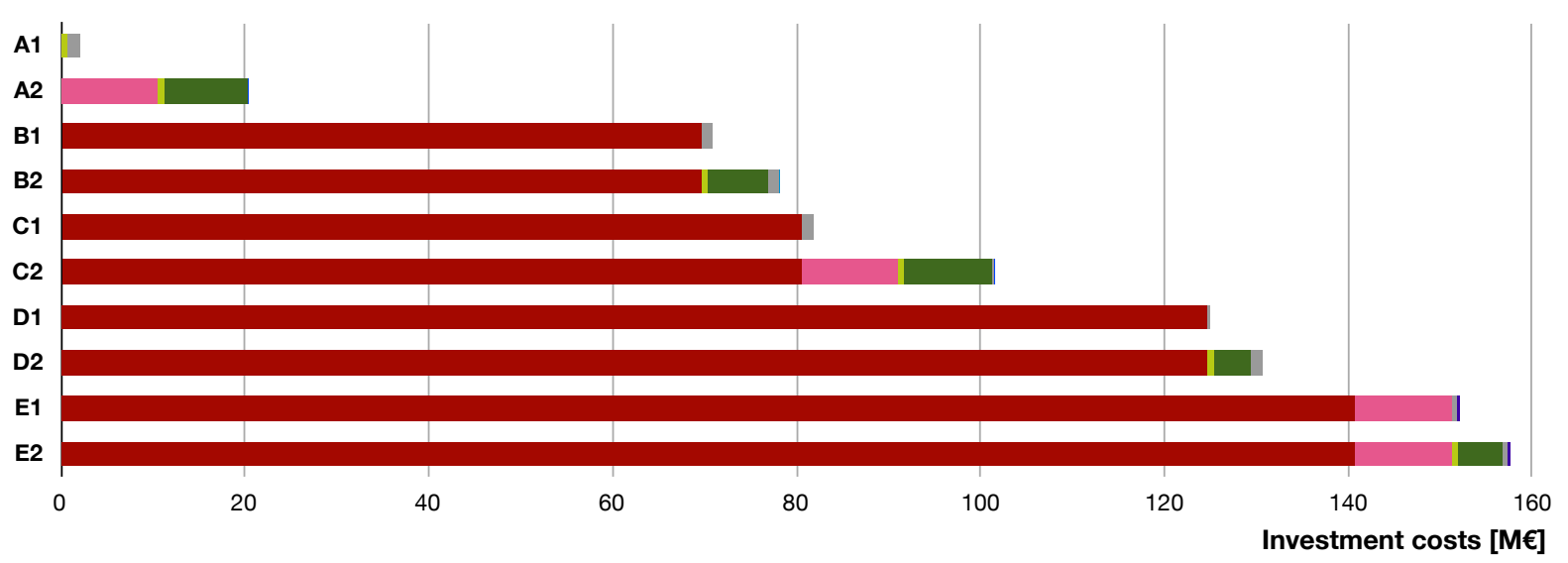

घGS Deep aquifer Biomethanation $\square$ SNG from wood Boiler Nat. Gas $\square$ Engine Nat. Gas $\square$ Engine biogas $\square$ Turbine biogas

(a) Investment costs

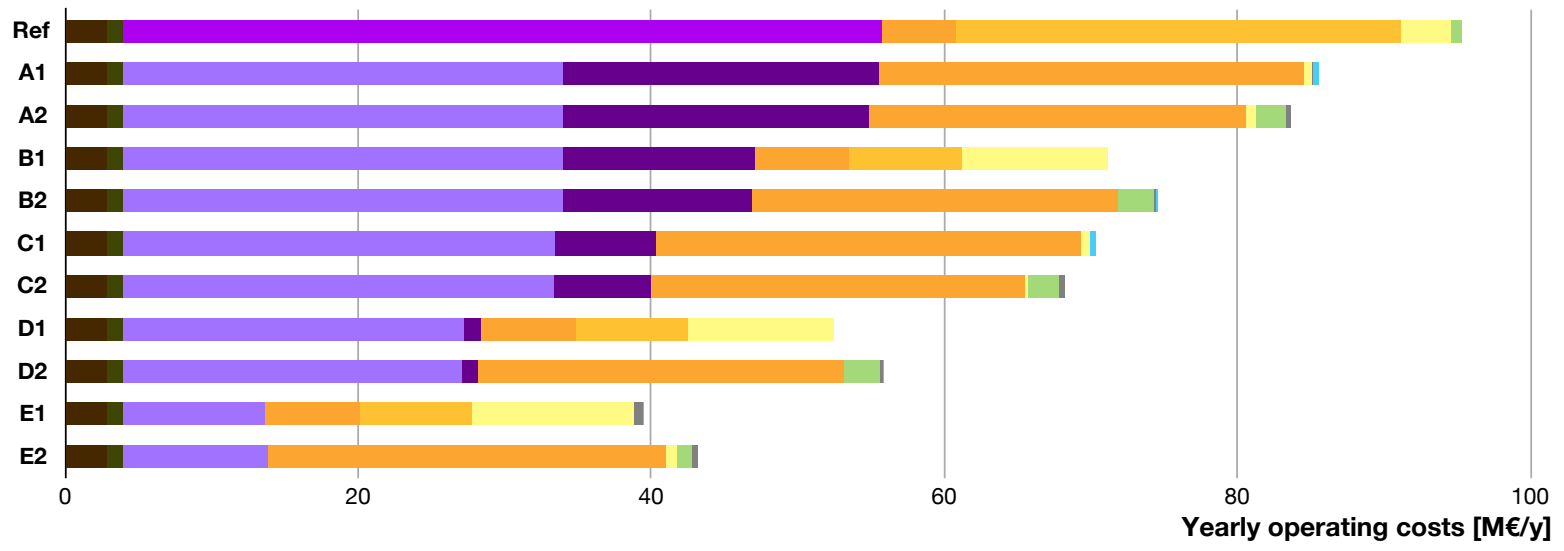

MSWI WWTP Elec. Swiss mix Elec. hydro $\square$ Elec. UCTE Diesel Petrol Natural Gas Wood Technologies CO2 tax

(b) Yearly operating costs

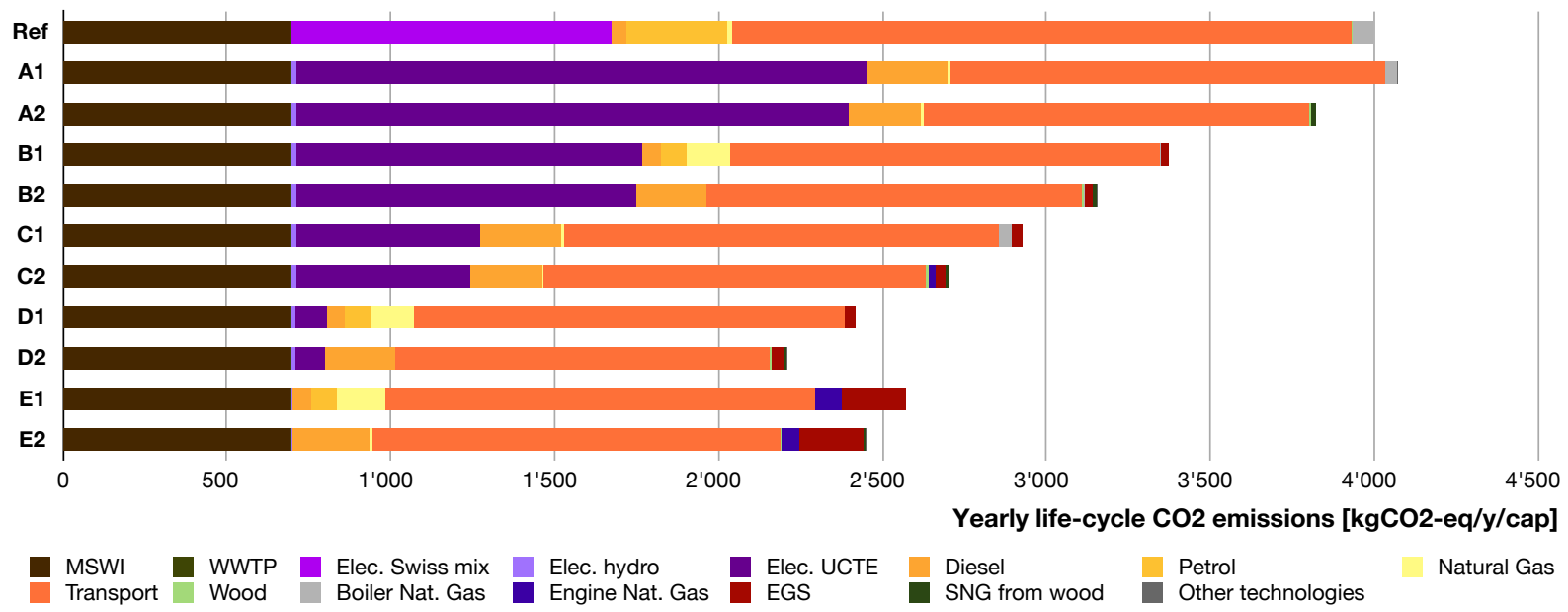

(c) Yearly life-cycle $\mathrm{CO}_{2}$ emissions per capita

Figure 8: Comparison of typical optimal configurations from the Pareto curve of Figure 6 . (a) Investment costs (b) Yearly operating costs (c) Yearly life-cycle $\mathrm{CO}_{2}$ emissions per capita.

heat usage from the WWTP, the consumption of hydro-electricity and the usage of the deep aquifer and of the natural gas engine are adapted to the energy service requirements and to operation of the MSWI plant.

During the first summer period, the district heating requirement is low and can be satisfied by the waste treatment facilities, as seen on Figure 9(a). For the MSWI plant, the emphasis is 


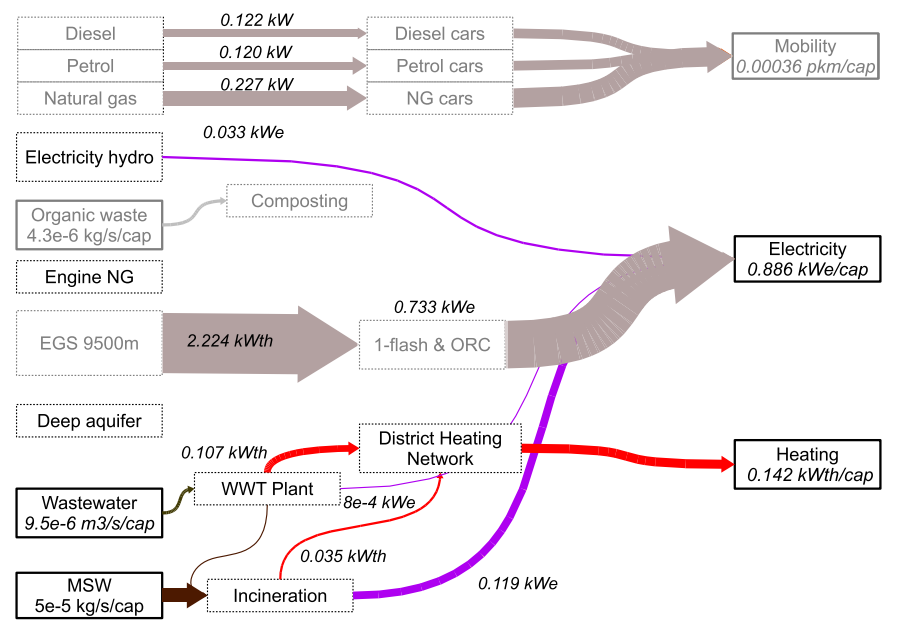

(a) Period 1 (May, July \& August)

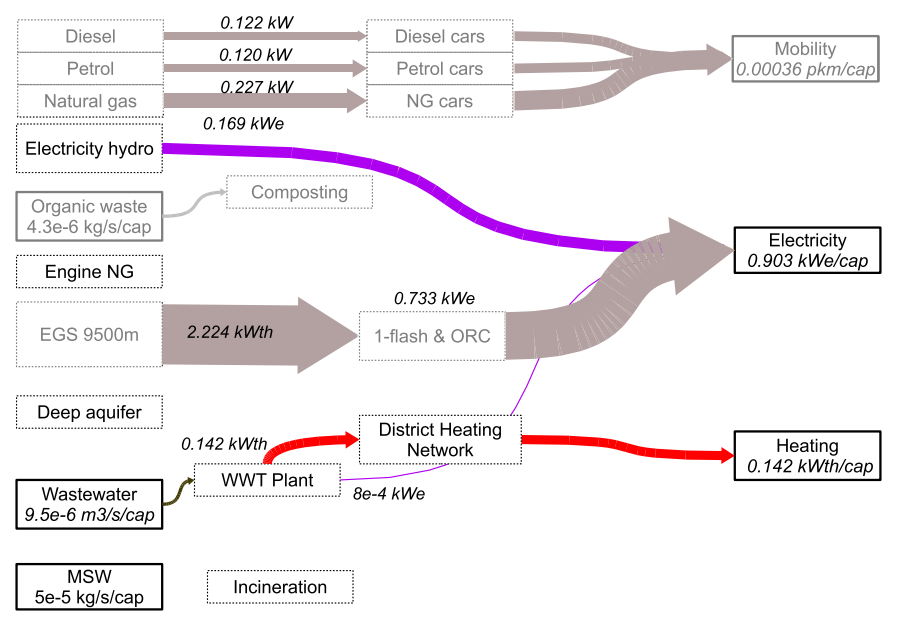

(b) Period 2 (June)

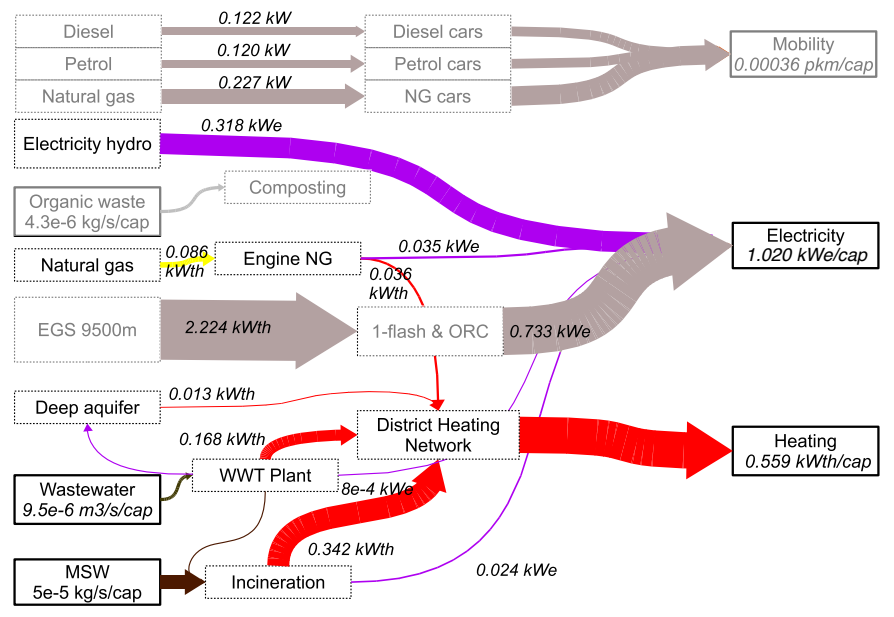

(c) Period 5 (November-February)

Figure 9: Examples of seasonal operation per capita for configuration E1: (a) Period 1 (May, July \& August) (b) Period 2 (June) (c) Period 5 (November-February)

thus put on the electricity production, and only a small import of hydro-electricity is necessary.

During the second summer period, the MSWI plant is shut down for revision. The district heating requirement being still low, more heat from the WWTP is used to compensate the non-operation of the MSWI plant, as seen on Figure 9(b). The district heating is thus still 
supplied only with local sources from waste treatment. For the electricity production, more hydro-electricity is consumed to compensate the shut down of the MSWI plant.

During the winter period, the district heating requirement increases by $400 \%$ compared to the summer requirement, while the electricity requirement increases only by $25 \%$. Therefore, the operating conditions of the MSWI plant are adapted to favor heat over electricity production, as seen on Figure 9(c). The WWTP supplies slightly more heat, but is limited by the higher temperature of the district heating network. Part of the low-temperature heat is as well supplied by the deep aquifer, and part of the high-temperature heat by the exhaust gases of a natural gas engine. Part of the electricity is supplied by the natural gas engine, by the MSWI plant with a reduced share, and by hydro-electricity.

Pathways for resources and waste conversion Another application of the developed methodology is the identification of optimal pathways for resource or waste conversion and allocation, accounting for the limited availability of waste and of indigenous resources. This is illustrated by configuration D2 and its biomass usage, including organic waste and woody biomass. The system operation per capita is displayed in Figure 10 for the first summer period. The pathways for biomass conversion are highlighted and their flows displayed in color, while the other technologies are shaded and their flows displayed in grey.

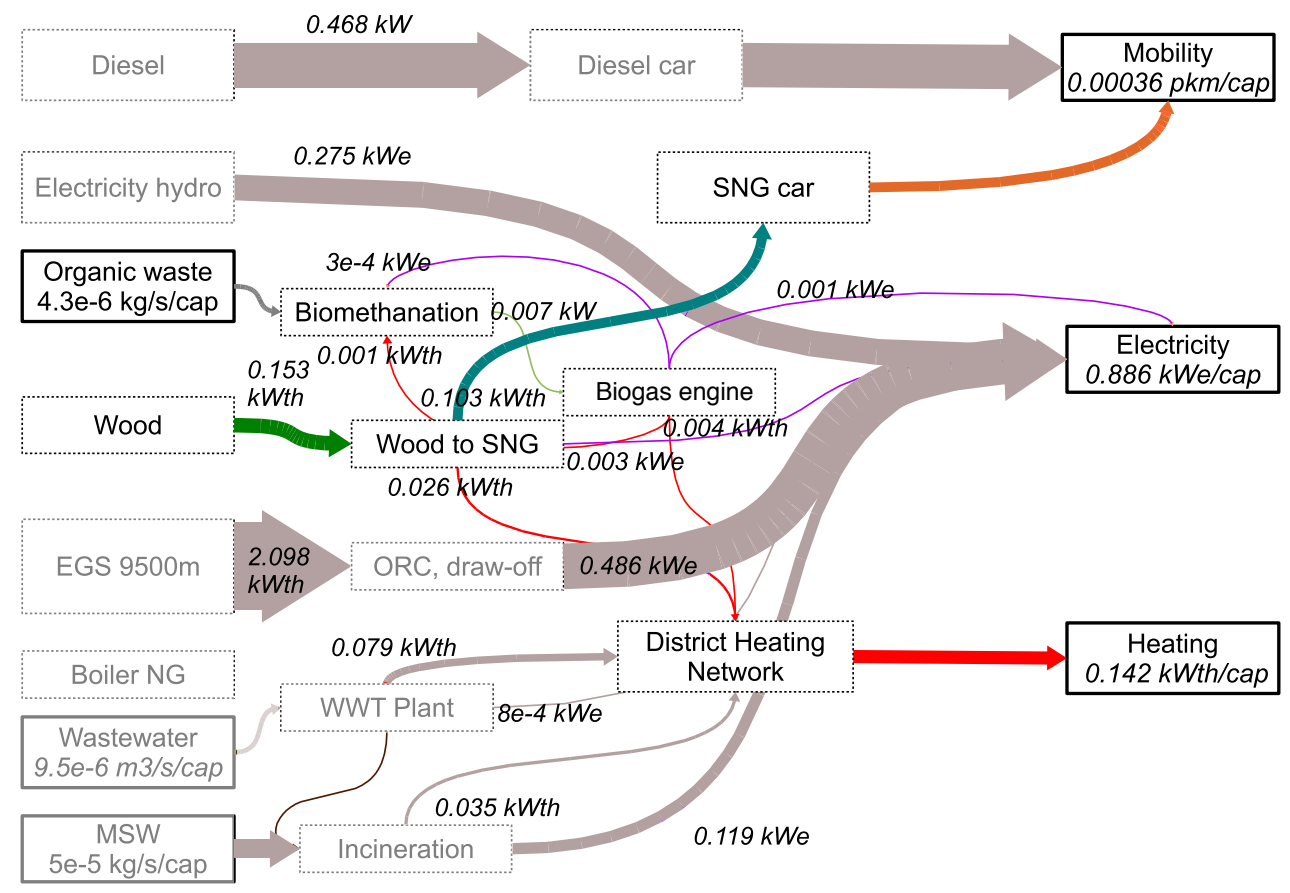

Figure 10: Example of optimal pathways for organic waste and woody biomass conversion for configuration D2 during period 1 (May, July \& August).

As seen from Figure 10, the optimal pathway for woody biomass is its conversion to combined electricity, heat and SNG. The SNG being used for transport, the woody biomass contributes thus to the three services. The optimal pathway for organic waste is the conversion to biogas, used for the cogeneration of heat and electricity. However, the diagram shows as well the limited potential of biomass. Indeed, the contribution to electricity and heat requirement of organic waste is insignificant. Regarding woody biomass used to its full potential here, its contribution to the transport is $13.7 \%$, its contribution to the district heating between $18.3 \%$ and $4.7 \%$, depending on the period, and its contribution to the electricity inferior to $1 \%$. The relative reduction in yearly $\mathrm{CO}_{2}$ emissions that can be attributed directly to the optimal biomass usage is around $5 \%$ when compared with the current situation. 
By analyzing the points of the Pareto curve, it is as well possible to identify the pathways that are selected in some others of the optimal configurations, and the ones that are never selected. This is illustrated in Figure 11. Among all the potential pathways for woody biomass (Fig. 11(a)) and for organic waste (Fig. 11(b)), it shows which ones are selected at least in one of the optimal configurations. The non-selected suboptimal pathways are shaded. For readability, only the main flows are displayed.

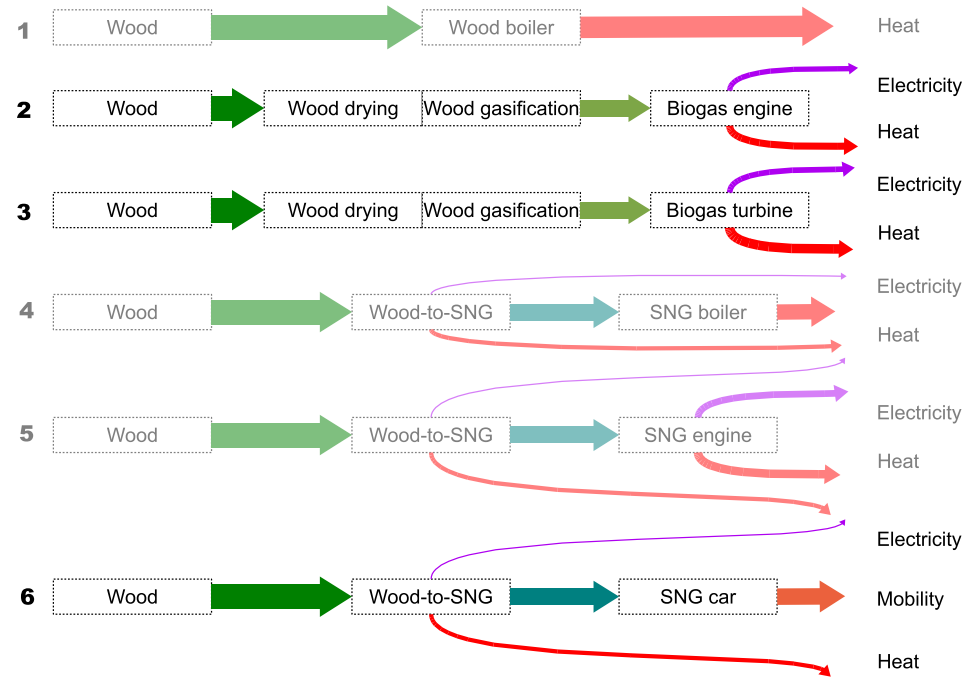

(a) Woody biomass

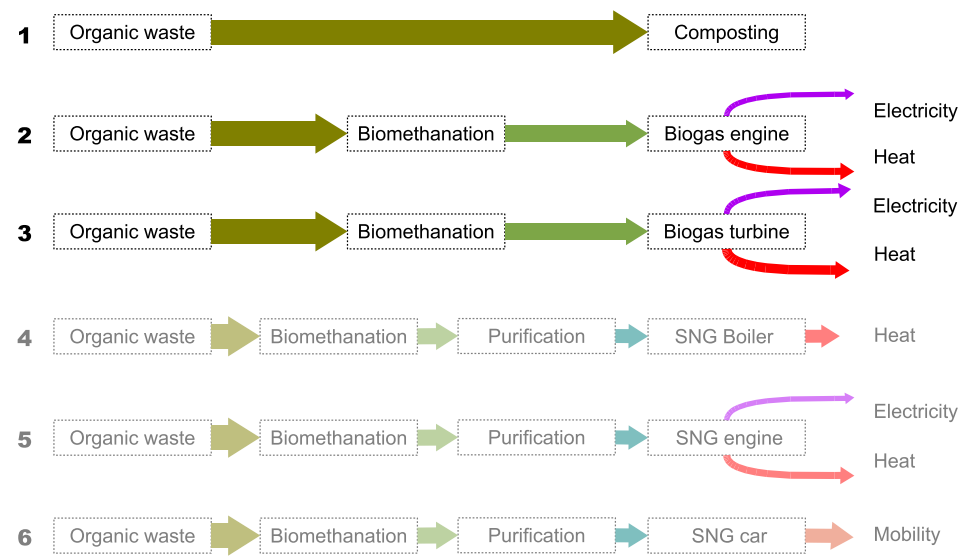

(b) Organic waste

Figure 11: Selected pathways in the optimal configurations of the Pareto curve for biomass conversion: (a) woody biomass (b) organic waste. The suboptimal non-selected pathways are shaded.

For woody biomass, the selected pathways are the conversion to SNG, electricity and heat for transport applications (6) in most of the environomic configurations. In a few cases of cluster $\mathrm{A}, \mathrm{B}$ and $\mathrm{C}$, the gasification and use in a biogas engine or turbine for CHP $(2,3)$ are as well selected. The transport usage of biomass is favored over the other ones, since other alternatives are embedded in the superstructure for heat and electricity production, such as the MSWI plant or the geothermal technologies. The production of heat in a wood boiler (1), used in the current situation, or the production of SNG and its use in a boiler for heat production (4), or in an engine for CHP (5), are not optimal pathways in the present case. For organic waste, the production of biogas through biomethanation and its purification to SNG $(4,5,6)$ are not selected due to the high investment cost of a purification unit and the very limited potential of organic waste. Thus, the optimal pathways for organic waste are either the composting (1), used in the current 
situation, or the biomethanation and the use of the biogas in an engine or a turbine for CHP $(2,3)$.

Selection of technologies The developed methodology allows as well for selecting the optimal technologies for resource valorization. This is illustrated by the example of geothermal energy technologies. Table 5 shows which ones are selected in the optimal configurations of the Pareto curve.

\begin{tabular}{|l|l|}
\hline Pathway & Represented in Pareto \\
\hline Deep aquifer 1450m, direct heat usage & yes (all clusters) \\
Deep aquifer 1450m, heat pumps & no \\
EGS $6000 \mathrm{~m}$, Kalina for CHP & yes (cluster B) \\
EGS $6500 \mathrm{~m}$, supercritical ORC for electricity production & yes (cluster C) \\
EGS $8000 \mathrm{~m}, 2$-flash for CHP & no \\
EGS 9500m, ORC with draw-off for CHP & yes (cluster D) \\
EGS 9500m, 1-flash \& bottoming ORC for electricity production & yes (cluster E) \\
\hline
\end{tabular}

Table 5: Selection of geothermal technologies embedded in the superstructure for the optimal system configurations of the Pareto curve

A part of the available heat from the deep aquifer is directly used to supply low temperature heat to the district heating network. The use of heat pumps for supplying higher temperature heat from the aquifer is not considered, since it would increase the investment costs and the electricity consumption. For EGS, the only technology not selected is the double-flash for CHP with an EGS at $8000 \mathrm{~m}$. Indeed, this solution is suboptimal compared to the other EGS technologies in terms of operating costs and of environmental impacts. This is due to the high maintenance costs linked with a large double-flash system and to the fossil $\mathrm{CO}_{2}$ emissions from the condensers (see Gerber and Maréchal (2012b) for more details).

Competition and synergies A last aspect of the developed methodology is the use of a systems approach accounting for the interactions between the different supply chains. This allows for identifying the potential competitions or synergies between different resources and technologies.

An example of competition is the supplementary heat requirement for the district heating in winter, which can not be fully satisfied by the MSWI plant and the WWTP. This supplementary heat requirement can either be supplied by the deep aquifer, or a natural gas engine or boiler, or the wood-to-SNG conversion unit, or the heat from the EGS if this one is used for CHP. All these pathways are competing. This is illustrated by Figure 12, showing the system operation at period 5 for two configurations. The other technologies are shaded, and their flows are displayed in grey.

For the first configuration, the EGS is exclusively used for electricity production and the wood-to-SNG conversion unit is turned off, as seen on Figure 12(a). Moreover, the full potential of low-temperature heat from the WWTP is used. The deep aquifer and the natural gas engine are thus used to supply the supplementary heat requirement. For the second configuration, the EGS is used for CHP and the wood-to-SNG conversion unit is turned on, as seen on Figure 12(b). These two heat sources and the WWTP are sufficient to supply the supplementary heat requirements. Thus, the investment in the deep aquifer or in the natural gas engine is not necessary. Though this configuration allows for a full supply of the district heating network from waste or renewable sources, part of the electricity has to be supplied by the import of UCTE mix.

In all the typical optimal configurations, the deep aquifer is competing with the EGS configurations used for CHP and with the heat from the wood-to-SNG conversion unit. 


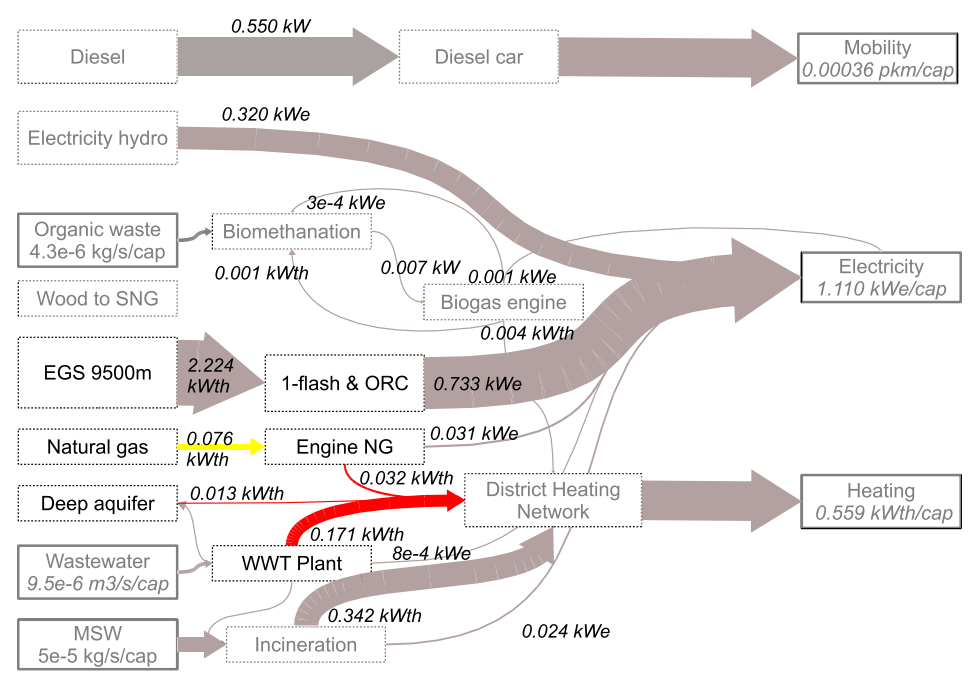

(a) Configuration E2 (EGS for electricity production only)

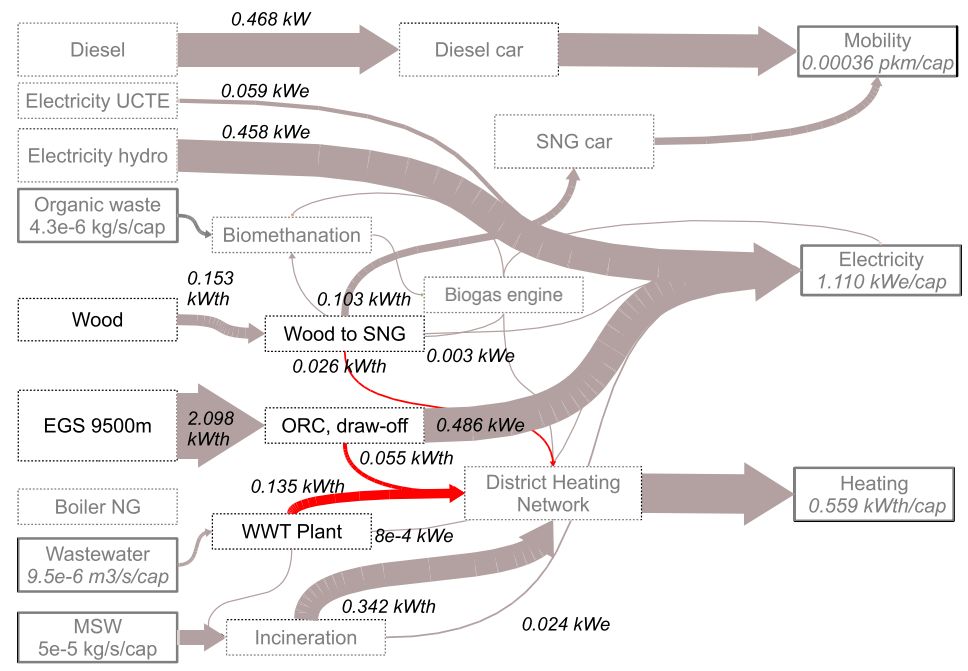

(b) Configuration D2 (EGS for heat and power production and woodto-SNG conversion)

Figure 12: Heat production from different resources and technologies during period 5 (NovemberFebruary) for two configurations: (a) Configuration E2 (b) Configuration D2

An example of synergy is the interaction between the MSWI plant and the WWTP during summer. Indeed, using the heat produced by the WWTP reduces the supplementary requirement of the district heating network. Then, it can be satisfied by using only a small part of the heat from the MSWI plant, as seen on Figure 9(a). The remaining part of the heat from waste incineration is thus available for an increased electricity production.

\subsubsection{Optimal value of $\mathrm{CO}_{2}$ tax}

In order to perform a final selection in the optimal configurations of the Pareto curve, the economic indicator of the payback period (Eq. (14)) and the environmental indicator of the reduction in $\mathrm{CO}_{2}$ emissions (Eq. (15)) are used. As displayed in Figure 13, if the raw results from the optimization are used, the economic optimum is the configuration A1 $\left(t_{p b}=0.41 \mathrm{y}\right)$, with almost no investment and only an adjustment of the system operating conditions. However, it is the worse one from an environmental point of view, since it increases slightly the $\mathrm{CO}_{2}$ emissions $\left(R c o 2_{I}=-1.9 \%\right)$ due to the import of UCTE mix. In order to move the economic optimum to a configuration achieving a better environmental performance, the $\mathrm{CO}_{2}$ tax can be 
adjusted and the payback period recalculated. In the present case, the configuration A1 remains the economic optimum up to a $\mathrm{CO}_{2}$ tax of $0.06 € / \mathrm{kgCO}_{2}$-eq. As displayed in Figure 13, the economic optimum becomes then the configuration E1 $\left(t_{p b}=6.0 \mathrm{y}\right)$, which has an environmental performance $\left(R c o 2_{I}=36 \%\right)$ closer to the environmental optimum, the configuration D2 $\left(t_{p b}=\right.$ $\left.7.5 \mathrm{y}, R c o 2_{I}=45 \%\right)$.

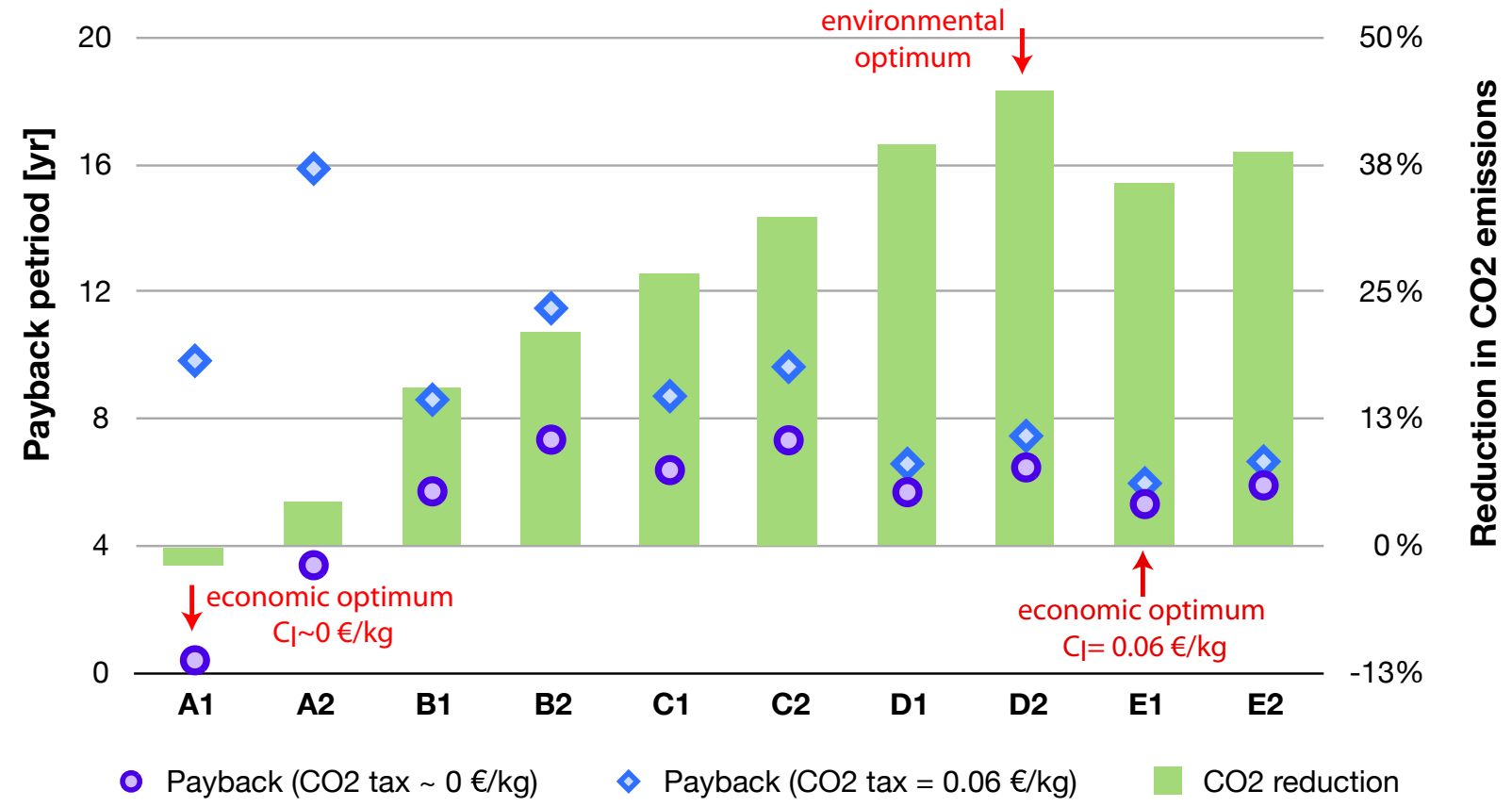

Figure 13: Reduction in $\mathrm{CO}_{2}$ emissions and payback period of typical optimal configurations from the Pareto curve of Figure 6

For a $\mathrm{CO}_{2}$ tax corresponding to $0.06 € / \mathrm{kgCO}_{2}$-eq, the environmental penalty to pay for choosing the economic optimum (E1) instead of the environmental optimum (D2) is a $20 \%$ relative decrease of the $\mathrm{CO}_{2}$ reduction. The economic penalty for choosing the environmental optimum instead of the economic one is a $25 \%$ increase in the payback period, which is a higher one. If one wanted to give a similar importance to the economic and environmental performance, the penalty would be shared. The configuration D1, with the $9500 \mathrm{~m}$ EGS for CHP without wood-to-SNG conversion, would realize the best trade-off between the two criteria, with relative penalties of $10 \%$ and $12 \%$ for the economic and environmental performances, respectively.

Though the optimal value for the $\mathrm{CO}_{2}$ tax identified by the multi-objective optimization is around zero, this analysis demonstrates however that such a tax is still necessary for selecting environomic system configurations rather than pure economic ones in the final design and planning of urban energy systems.

\section{Conclusions}

A systematic methodology for the design and synthesis of energy systems has been presented in this paper, combining process design and process integration, Life Cycle Assessment (LCA), industrial ecology and multi-objective optimization. It extends the decision perimeter to the supply chains involved in the system design, and allows for integrating a disaggregated LCI database to include models of average market technologies inside the superstructure. The methodology has been illustrated by an application case study dealing with the environomic design and synthesis of an urban energy system. It considers multiple services, waste to be treated, available resources and conversion technologies. 
A first important outcome is that the full integration of the environmental impact in the design and optimization procedure leads to consider a panel of optimal configurations that would not be considered in a pure economic optimization. Indeed, resources and technologies allowing to reach a higher impact reduction are represented in the optimal configurations. Moreover, while the maximum impact reduction for pure economic solutions is of $39.5 \%$, a higher impact reduction up to $44.8 \%$ is achieved with environomic solutions.

Secondly, the case study illustrates the necessity of considering an extended action perimeter for complex systems, embedding the different services to be supplied, the waste to be treated, the available indigenous or imported resources and the potential conversion technologies as separate units in the superstructure. This allows for synthesizing the optimal supply chains for the valorization of waste and resources, by accounting for the seasonal variations, for the limited availability of waste and of indigenous resources, and for the possible competitions and synergies between the different supply chains. In the present case, the operation of the waste treatment facilities can be adapted to the seasonal demand in district heating in order to minimize the consumption of other resources for heat supply. The optimal pathway for woody biomass conversion is a good example for the valorization of a limited indigenous resource. Since other local and competitive alternatives are available for electricity and heat production, such as the waste treatment facilities and the geothermal resources, the best usage of wood is its conversion to SNG and its use in transport, for which no other low-carbon alternatives are available. This example demonstrates the importance to account for the different competitors when evaluating different pathways for the valorization of a limited resource, and to perform the adequacy between the resource availability and the demand in energy services.

Finally, it is as well demonstrated that the methodology can be used to make a preliminary calculation of the optimal value of environmental taxes in order to favor the selection based on economic criteria of configurations that are closer to the environmental optimum. In the present case study, the two optimums are in conflict if no $\mathrm{CO}_{2}$ tax is applied. The minimal value of the $\mathrm{CO}_{2}$ tax to switch the economic optimum closer to the environmental one is $0.06 € / \mathrm{kgCO}_{2}$-eq.

Though the methodology is promising and allows to make a preliminary system design using an engineering approach, it could be extended in future work to integrate other aspects inherent to complex systems, such as industrial parks, urban systems or territories. These include to deal with the uncertainties linked with such systems, and account for the multiplicity of stakeholders involved.

\section{References}

Allenby, B., Richards, D., 1994. The greening of industrial ecosystems. National Academy Press, Washington D.C., USA.

Becker, H., Maréchal, F., 2012. Energy integration of industrial sites with heat exchange restrictions. Computers \& Chemical Engineering 37, 104-118.

Berkel, R. V., Fujita, T., Hashimoto, S., Geng, Y., 2009. Industrial and urban symbiosis in Japan: Analysis of the Eco-Town program 1997-2006. Journal of Environmental Management 90, 1544-1556.

Cucek, L., Varbanov, P., Klemes, J., Kravanja, Z., 2012. Total footprint-based multi-criteria optimization of regional biomass energy supply chains. Energy 44, 135-145.

Davis, C., Nikolic, I., Dijkema, G., 2009. Integration of life cycle assessment into agent-based modeling. Journal of Industrial Ecology 13, 306-325.

Descoins, N., Deleris, S., Lestienne, R., Trouvé, E., Maréchal, F., 2012. Energy efficiency in waste water treatment plants: Optimization of activated sludge process coupled with anaerobic digestion . Energy 41, 153-164. 
Diwekar, U., Shastri, Y., 2010. Green process design, green energy, and sustainability: A systems analysis perspective. Computers \& Chemical Engineering 34, 1348-1355.

Doka, G., 2007. Life Cycle Inventories of Waste Treatment Services, ecoinvent report No 13. Tech. rep., ecoinvent center, CH-8600 Dübendorf, Switzerland.

Dones, R., Bauer, C., 2007. Life Cycle Inventories of Transport Services, ecoinvent report No 14. Tech. rep., ecoinvent center, CH-8600 Dübendorf, Switzerland.

Dones, R., Bauer, C., Bolliger, R., Burger, B., Heck, T., Röder, A., Emmenegger, M. F., Frischknecht, R., Jungbluth, N., Tuchschmid, M., 2007. Life Cycle Inventories of energy systems, ecoinvent report No 6 (in German). Tech. rep., ecoinvent center, CH-8600 Dübendorf, Switzerland.

Ehrenfeld, J., Gertler, N., 1997. Industrial Ecology in Practice. The Evolution of Interdependence at Kalundborg. Journal of Industrial Ecology 1, 67-79.

Fazlollahi, S., Maréchal, F., 2011. Multi-Objective, Multi-Period Optimization of Biomass Conversion Technologies Using Evolutionary Algorithms and Mixed Integer Linear Programming (MILP). Applied Thermal Engineering, doi:10.1016/j.applthermaleng.2011.11.035.

Frischknecht, R., Jungbluth, N., Althaus, H.-J., Doka, G., Dones, R., Heck, T., Hellweg, S., Hischier, R., Nemecek, T., Rebitzer, G., Spielmann, M., 2005. The ecoinvent database: Overview and methodological framework. International Journal of Life Cycle Assessment 10, 3-9.

Gassner, M., Gerber, L., Salgueiro, L., Maréchal, F., 2011. Perspectives of using distributed biogas in the natural gas grid - Report of the study carried out on behalf of the Environment and Energy Service (SEVEN) of the Canton of Vaud (in French). Tech. rep., Ecole Polytechnique Fédérale de Lausanne (EPFL), CH-1015 Lausanne, Switzerland.

Gassner, M., Maréchal, F., 2009a. Methodology for the optimal thermo-economic, multi-objective design of thermochemical fuel production from biomass. Computers \& Chemical Engineering 33, 769-781.

Gassner, M., Maréchal, F., 2009b. Thermo-economic process model for thermochemical production of Synthetic Natural Gas (SNG) from lignocellulosic biomass. Biomass and bioenergy 33, $1587-1604$.

Gerber, L., Gassner, M., Maréchal, F., 2011a. Systematic Integration of LCA in process systems design: Application to combined fuel and electricity production from lignocellulosic biomass. Computers \& Chemical Engineering 35, 1265-1280.

Gerber, L., Maréchal, F., 2011. Hybrid systems for the exploitation of deep geothermal resources: case study of La Chaux-de-Fonds - Report of the study carried out on behalf of the Laboratory for Geothermics (CREGE) of the University of Neuchâtel (in French). Tech. rep., Ecole Polytechnique Fédérale de Lausanne (EPFL), CH-1015 Lausanne, Switzerland.

Gerber, L., Maréchal, F., 2012a. Defining optimal configurations of geothermal systems using process design and process integration techniques. Applied Thermal Engineering 43, 29-41.

Gerber, L., Maréchal, F., 2012b. Environomic optimal configurations of geothermal energy conversion systems: application to the future construction of Enhanced Geothermal Systems in Switzerland. Energy 45, 908-923.

Gerber, L., Mayer, J., Maréchal, F., 2011b. A systematic methodology for the synthesis of unit process chains using Life Cycle Assessment and Industrial Ecology Principles. Computer Aided Chemical Engineering 29, 1215-1219. 
Girardin, L., Maréchal, F., Dubuis, M., Calame-Darbellay, N., Favrat, D., 2010. EnerGis: A geographical information based system for the evaluation of integrated energy conversion systems in urban areas. Energy 35, 830-840.

Guillén-Gosálbez, G., Caballero, J., Jiménez, L., 2008. Application of Life Cycle Assessment to the Structural Optimization of Process Flowsheets. Industrial and Engineering Chemistry Research 47, 777-789.

Guillén-Gosálbez, G., Grossmann, I., 2010. A global optimization strategy for the environmentally conscious design of chemical supply chains under uncertainty in the damage assessment model. Computers \& Chemical Engineering 34, 42-58.

Hugo, A., Pistikopoulos, E., 2005. Environmentally conscious long-range planning and design of supply chain networks. Journal of Cleaner Production 13, 1471-1491.

ISO, 2006a. Environmental management - Life Cycle Assessment - Principles and framework. International Standard, ISO 14'040.

ISO, 2006b. Environmental management - Life Cycle Assessment - Requirements and guidelines. International Standard, ISO 14'044.

Jungbluth, N., Chudacoff, M., Dauriat, A., Dinkel, F., Doka, G., Emmenegger, M. F., Gnansounou, E., Kljun, N., Spielmann, M., Stettler, C., Sutter, J., 2007. Life Cycle Inventories of Bioenergy, ecoinvent report No 17. Tech. rep., ecoinvent center, CH-8600 Dübendorf, Switzerland.

Linnhoff, B., Townsend, D., Boland, D., Hewitt, G., Thomas, B., Guy, A., Marsland, R., 1982. User Guide on Process Integration for the Efficient Use of Energy. The Institution of Chemical Engineers, Rugby, Warks, England.

Maréchal, F., Kalitventzeff, B., 1998. Process integration: Selection of the optimal utility system. Computers \& Chemical Engineering 22, S149-S156.

Mattila, T., Lehtoranta, S., Sokka, L., Melanen, M., Nissinen, A., 2012. Methodological Aspects of Applying Life Cycle Assessment to Industrial Symbioses. Journal of Industrial Ecology 16, $51-60$.

Molyneaux, A., Leyland, G., Favrat, D., 2010. Environomic multi-objective optimisation of a district heating network considering centralized and decentralized heat pumps. Energy 35, $751-758$.

Muller, E., Kobel, B., Schmid, F., 2008. Energy in Wastewater Treatment Plants (in French). Tech. rep., Suisse Energie (Swiss Federal Office of Energy), Bern, Switzerland.

OFEN, 2010. Swiss statistics of electricity 2010 (in French). Tech. rep., Swiss Federal Office of Energy, Bern, Switzerland.

OStat, 2010. Mobility and transportation 2010 (in French). Tech. rep., Swiss Federal Office of Statistics, Bern, Switzerland.

Primas, A., 2007. Life Cycle Inventories of new CHP systems, ecoinvent report No 20. Tech. rep., ecoinvent center, CH-8600 Dübendorf, Switzerland.

Singh, A., Lou, H. H., Yaws, C. L., Hopper, J., Pike, R., 2007. Environmental impact assessment of different design schemes of an industrial ecosystem. Resources, Conservation \& Recycling $51,294-313$. 
Steubing, B., Zah, R., Waeger, P., Ludwig, C., 2010. Bioenergy in switzerland: Assessing the domestic sustainable biomass potential. Renewable and Sustainable Energy Reviews 14, 22562265 .

Urban, R., Bakshi, B., Grubb, G., Baral, A., Mitsch, W., 2010. Towards sustainability of engineered processes: Designing self-reliant networks of technological-ecological systems. Computers and Chemical Engineering 34, 1413-1420.

Working group PDGN, 2010. Cantonal program for the development of geothermal energy in Neuchâtel: Final report (in French). Tech. rep., Laboratory for Geothermics - CREGE, CH2000 Neuchâtel, Switzerland.

\section{Appendix}

\begin{tabular}{|c|c|c|c|}
\hline Model name & Model type & & Model sources \\
\hline Biomethanation & LCI database & & $\begin{array}{l}\text { Jungbluth et al. (2007); Gassner } \\
\text { et al. (2011) }\end{array}$ \\
\hline Boiler, oil & $\begin{array}{l}\text { Flowsheeting } \\
\text { ware }\end{array}$ & soft- & $\begin{array}{l}\text { Fazlollahi and Maréchal (2011); } \\
\text { Dones et al. (2007) }\end{array}$ \\
\hline Boiler, natural gas & $\begin{array}{l}\text { Flowsheeting } \\
\text { ware }\end{array}$ & soft- & $\begin{array}{l}\text { Fazlollahi and Maréchal (2011); } \\
\text { Dones et al. (2007) }\end{array}$ \\
\hline Boiler, wood & $\begin{array}{l}\text { Flowsheeting } \\
\text { ware }\end{array}$ & soft- & $\begin{array}{l}\text { Fazlollahi and Maréchal (2011); } \\
\text { Dones et al. (2007) }\end{array}$ \\
\hline Car, diesel & LCI database & & Dones and Bauer (2007) \\
\hline Car, natural gas & LCI database & & Dones and Bauer (2007) \\
\hline Car, petrol & LCI database & & Dones and Bauer (2007) \\
\hline Dam (hydro-electricity) & LCI database & & Dones et al. (2007) \\
\hline Dryers, wood & $\begin{array}{l}\text { Flowsheeting } \\
\text { ware }\end{array}$ & soft- & $\begin{array}{l}\text { Fazlollahi and Maréchal (2011); } \\
\text { Gerber et al. (2011a) }\end{array}$ \\
\hline Engine, biogas & $\begin{array}{l}\text { Flowsheeting } \\
\text { ware }\end{array}$ & soft- & $\begin{array}{l}\text { Fazlollahi and Maréchal (2011); } \\
\text { Jungbluth et al. (2007) }\end{array}$ \\
\hline Engine, natural gas & $\begin{array}{l}\text { Flowsheeting } \\
\text { ware }\end{array}$ & soft- & $\begin{array}{l}\text { Fazlollahi and Maréchal (2011); } \\
\text { Dones et al. (2007) }\end{array}$ \\
\hline Flash systems (geothermal) & $\begin{array}{l}\text { Flowsheeting } \\
\text { ware }\end{array}$ & soft- & Gerber and Maréchal (2012a,b) \\
\hline Gasifiers, wood & $\begin{array}{l}\text { Flowsheeting } \\
\text { ware }\end{array}$ & soft- & $\begin{array}{l}\text { Fazlollahi and Maréchal (2011); } \\
\text { Gerber et al. (2011a) }\end{array}$ \\
\hline Heat pump & $\begin{array}{l}\text { Flowsheeting } \\
\text { ware }\end{array}$ & soft- & $\begin{array}{l}\text { Gerber and Maréchal (2012a); } \\
\text { Dones et al. (2007) }\end{array}$ \\
\hline Kalina cycle (geothermal) & $\begin{array}{l}\text { Flowsheeting } \\
\text { ware }\end{array}$ & soft- & Gerber and Maréchal (2012a,b) \\
\hline $\begin{array}{l}\text { Municipal solid waste incin- } \\
\text { eration }\end{array}$ & $\begin{array}{l}\text { Flowsheeting } \\
\text { ware }\end{array}$ & soft- & $\begin{array}{l}\text { Gerber and Maréchal (2011); Doka } \\
(2007)\end{array}$ \\
\hline $\begin{array}{l}\text { Organic Rankine cycles } \\
\text { (geothermal) }\end{array}$ & $\begin{array}{l}\text { Flowsheeting } \\
\text { ware }\end{array}$ & soft- & Gerber and Maréchal (2012a,b) \\
\hline Purification of biogas & LCI database & & $\begin{array}{l}\text { Jungbluth et al. (2007); Gassner } \\
\text { et al. (2011) }\end{array}$ \\
\hline $\begin{array}{l}\text { Thermochemical wood-to- } \\
\text { SNG conversion }\end{array}$ & LCI database & & $\begin{array}{l}\text { Gassner and Maréchal (2009b); } \\
\text { Gerber et al. (2011a) }\end{array}$ \\
\hline Turbine, biogas & $\begin{array}{l}\text { Flowsheeting } \\
\text { ware }\end{array}$ & soft- & $\begin{array}{l}\text { Fazlollahi and Maréchal (2011); } \\
\text { Primas (2007) }\end{array}$ \\
\hline Wastewater treatment plant & $\begin{array}{l}\text { Flowsheeting } \\
\text { ware }\end{array}$ & soft- & Descoins et al. (2012); Doka (2007) \\
\hline
\end{tabular}

Table 6: Sources used for the different models of the conversion technologies included in the urban systems superstructure 


\begin{tabular}{|l|l|l|}
\hline Model name & Model type & Model sources \\
\hline Deep aquifer & Flowsheeting soft- & Gerber and Maréchal (2012a,b) \\
ware Dry Rock (EGS) & Flowsheeting soft- & Gerber and Maréchal (2012a,b) \\
& ware & \\
Woody biomass & LCI database & Dones et al. (2007) \\
Water (hydro) & LCI database & Dones et al. (2007) \\
Natural gas & LCI database & Dones et al. (2007) \\
Petrol & LCI database & Dones et al. (2007) \\
Diesel & LCI database & Dones et al. (2007) \\
Oil & LCI database & Dones et al. (2007) \\
Electricity UCTE import & LCI database & Dones et al. (2007) \\
\hline
\end{tabular}

Table 7: Sources used for the different models of the resources included in the urban systems superstructure 